\title{
Tropical Intraseasonal Variability in 14 IPCC AR4 Climate Models. Part I: Convective Signals
}

\author{
Jia-Lin Lin, ${ }^{a}$ George N. Kiladis, ${ }^{b}$ Brian E. Mapes, ${ }^{c}$ Klaus M. Weickmann, ${ }^{a}$ Kenneth R. Sperber, ${ }^{d}$ \\ Wuyin Lin, ${ }^{\mathrm{e}}$ Matthew C. Wheeler,${ }^{\mathrm{f}}$ Siegfried D. Schubert, ${ }^{\mathrm{g}}$ Anthony Del Genio, ${ }^{\mathrm{h}}$ \\ Leo J. Donner, ${ }^{\mathrm{i}}$ Seita Emori, ${ }^{\mathrm{j}}$ Jean-Francois Gueremy, ${ }^{\mathrm{k}}$ Frederic Hourdin, ${ }^{\mathrm{l}}$ Philip J. Rasch, ${ }^{\mathrm{m}}$ \\ ERICH ROECKNER, ${ }^{\mathrm{n}}$ AND JOHN F. SCINOCCA ${ }^{\mathrm{O}}$

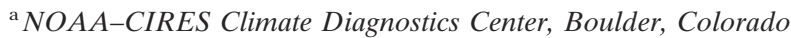 \\ ${ }^{\mathrm{b}}$ NOAA/Aeronomy Laboratory, Boulder, Colorado \\ ${ }^{\mathrm{c}}$ Rosenstiel School of Marine and Atmospheric Science, University of Miami, Miami, Florida \\ d Program for Climate Model Diagnosis and Intercomparison (PCMDI), Lawrence Livermore National Laboratory, \\ Livermore, California \\ e State University of New York-Stony Brook, Stony Brook, New York \\ ${ }^{\mathrm{f}}$ Bureau of Meteorlogy Research Centre, Melbourne, Australia \\ ${ }^{\mathrm{g}}$ Global Modeling and Assimilation Office, NASA GSFC, Greenbelt, Maryland \\ ${ }^{\mathrm{h}}$ NASA Goddard Institute for Space Studies, New York, New York \\ ${ }^{\mathrm{i}}$ NOAA/Geophysical Fluid Dynamics Laboratory, Princeton, New Jersey \\ ${ }^{\mathrm{j}}$ National Institute for Environmental Studies, Ibaraki, Japan \\ ${ }^{\mathrm{k}}$ Météo-France, CNRM, Toulouse, France \\ ${ }^{1}$ Laboratoire de Météorologie Dynamique, Université de Paris, Paris, France \\ ${ }^{\mathrm{m}}$ National Center for Atmospheric Research, Boulder, Colorado \\ ${ }^{\mathrm{n}}$ Max Planck Institute for Meteorology, Hamburg, Germany \\ ${ }^{\circ}$ Canadian Centre for Climate Modelling and Analysis, Victoria, Canada
}

(Manuscript received 18 May 2005, in final form 20 October 2005)

\begin{abstract}
This study evaluates the tropical intraseasonal variability, especially the fidelity of Madden-Julian oscillation (MJO) simulations, in 14 coupled general circulation models (GCMs) participating in the Intergovernmental Panel on Climate Change (IPCC) Fourth Assessment Report (AR4). Eight years of daily precipitation from each model's twentieth-century climate simulation are analyzed and compared with daily satellite-retrieved precipitation. Space-time spectral analysis is used to obtain the variance and phase speed of dominant convectively coupled equatorial waves, including the MJO, Kelvin, equatorial Rossby (ER), mixed Rossby-gravity (MRG), and eastward inertio-gravity (EIG) and westward inertio-gravity (WIG) waves. The variance and propagation of the MJO, defined as the eastward wavenumbers 1-6, 30-70-day mode, are examined in detail.

The results show that current state-of-the-art GCMs still have significant problems and display a wide range of skill in simulating the tropical intraseasonal variability. The total intraseasonal (2-128 day) variance of precipitation is too weak in most of the models. About half of the models have signals of convectively coupled equatorial waves, with Kelvin and MRG-EIG waves especially prominent. However, the variances are generally too weak for all wave modes except the EIG wave, and the phase speeds are generally too fast, being scaled to excessively deep equivalent depths. An interesting result is that this scaling is consistent within a given model across modes, in that both the symmetric and antisymmetric modes scale similarly to a certain equivalent depth. Excessively deep equivalent depths suggest that these models may not have a large enough reduction in their "effective static stability" by diabatic heating.

The MJO variance approaches the observed value in only 2 of the 14 models, but is less than half of the observed value in the other 12 models. The ratio between the eastward MJO variance and the variance of its westward counterpart is too small in most of the models, which is consistent with the lack of highly coherent eastward propagation of the MJO in many models. Moreover, the MJO variance in 13 of the 14 models does not come from a pronounced spectral peak, but usually comes from part of an overreddened spectrum, which in turn is associated with too strong persistence of equatorial precipitation. The two models that arguably do best at simulating the MJO are the only ones having convective closures/triggers linked in some way to moisture convergence.
\end{abstract}

Corresponding author address: Dr. Jia-Lin Lin, NOAA-CIRES Climate Diagnostics Center, 325 Broadway, R/CDC1, Boulder, CO 80305-3328.

E-mail: jialin.lin@noaa.gov 


\section{Introduction}

More than one-third of the earth's precipitation falls in the equatorial belt between $15^{\circ}$ north and $15^{\circ}$ south, and the released latent heat plays an important role in driving tropical circulations and in supplying energy to balance the radiative heat losses and "fuel" the wind systems of middle and high latitudes (e.g., Simpson et al. 1988). It is well known that precipitation in the equatorial belt does not occur randomly, but is often organized by convectively coupled large-scale equatorial waves, such as the Madden-Julian oscillation (MJO; Madden and Julian 1971), Kelvin, equatorial Rossby (ER), mixed Rossby-gravity (MRG), and eastward inertio-gravit (EIG) and westward inertio-gravity (WIG) waves (e.g., Takayabu 1994; Wheeler and Kiladis 1999, hereafter WK).

The MJO is the dominant tropical intraseasonal mode and a key source of untapped predictability in both the Tropics and extratropics (e.g., WK; Wheeler and Weickmann 2001; Schubert et al. 2002; Waliser et al. 2003a; Waliser 2005; see schematic in Fig. 1). The MJO is characterized by a convectively "forced" and highly viscous Kelvin-Rossby wave moving eastward from the western Indian Ocean to the date line with a slow phase speed of about $5 \mathrm{~m} \mathrm{~s}^{-1}$ (e.g., Knutson and Weickmann 1987; Wang and Rui 1990; Salby and Hendon 1994; Lin et al. 2005). The MJO often excites in the eastern Pacific a fast dry Kelvin mode with a phase speed of about $50 \mathrm{~m} \mathrm{~s}^{-1}$ (e.g., Madden and Julian 1972; Weickmann et al. 1997), and in northern summer there is often a local amplification of the MJO over the eastern Pacific ITCZ near Central America (Knutson and Weickmann 1987; Maloney and Hartmann 2000). The MJO significantly affects a wide range of tropical weather such as the onset and breaks of the Indian and Australian summer monsoons (e.g., Yasunari 1979; Wheeler and McBride 2005), and the formation of tropical cyclones in almost all basins (e.g., Liebmann et al. 1994; Maloney and Hartmann 2001a). Being a strong tropical heating source, the MJO also drives teleconnections to the extratropics (e.g., Weickmann et al. 1985; Berbery and Nogues-Paegle 1993) and impacts precipitation events in both the western United States (e.g., Mo and Higgins 1998; Higgins et al. 2000) and South America (e.g., Paegle et al. 2000; Jones and Schemm 2000). It also appears to affect both the Arctic Oscillation and Antarctic Oscillation (e.g., Miller et al. 2003; Carvalho et al. 2005). On a longer time scale, the MJO has been implicated in the triggering or termination of some El Niño events (e.g., Kessler et al. 1995; Takayabu et al. 1999; Bergman et al. 2001). Therefore, the MJO is important for both weather prediction and climate prediction.

Unfortunately, poor simulation of the MJO is a fairly generic problem in GCMs. Typically, model MJOs are too weak and propagate too fast (e.g., Hayashi and Sumi 1986; Hayashi and Golder 1986, 1988; Lau et al. 1988; Slingo et al. 1996). The Atmospheric Model Intercomparison Project (AMIP) study by Slingo et al. (1996) found that no model has captured the dominance of the MJO in space-time spectral analysis found in observations, and nearly all have relatively more power at higher frequencies ( $<30$ days) than in observations. Recently, several models have gotten stronger MJO variance and/or more coherent eastward propagation (e.g., Lee et al. 2001, 2003; Maloney and Hartmann 2001b; Waliser et al. 2003b; Sperber et al. 2005; C. Zhang et al. 2005, manuscript submitted to Climate Dyn.; Zhang and Mu 2005). However, as pointed by Waliser et al. (2003b), when a model does exhibit a relatively good $\mathrm{MJO}$, one can at best only give vague or plausible explanations for its relative success. This inhibits the extension of current model success to future versions.

Factors hypothesized to be important for MJO simulations include model physics, model resolution, and air-sea coupling. Previous modeling studies showed that MJO simulations are quite sensitive to changes in model physics, especially the deep convection scheme. Slingo et al. (1996) found that schemes with convective available potential energy (CAPE) type closure tend to produce more realistic MJO signals. Improvements of MJO simulations were also found by adding moisture triggers to the deep convection schemes (e.g., Tokioka et al. 1988; Wang and Schlesinger 1999; Lee et al. 2003), or by including convective downdrafts and convective rain evaporation (Maloney and Hartmann 2001b). Other aspects of model physics may also be important for the MJO simulation, such as the vertical heating profile (Park et al. 1990; Lin et al. 2004) and cloud radiative heating (Lee et al. 2001; Lin and Mapes 2004).

In addition to model physics, MJO simulation was found to be improved when using higher horizontal resolution (e.g., Kuma 1994) and/or vertical resolution (Inness et al. 2001). Coupling to the ocean has been found by many studies to improve the MJO signals (e.g., Flatau et al. 1997; Waliser et al. 1999; Sperber et al. 2005), although changes in a model's mean state need to be taken into account (e.g., Hendon 2000; Inness and Slingo 2003; Sperber et al. 2005). The mean state strongly affects wave-heating $>$ feedback in the MJO, for example, by providing the mean surface wind that determines the sign of the wind induced surface 


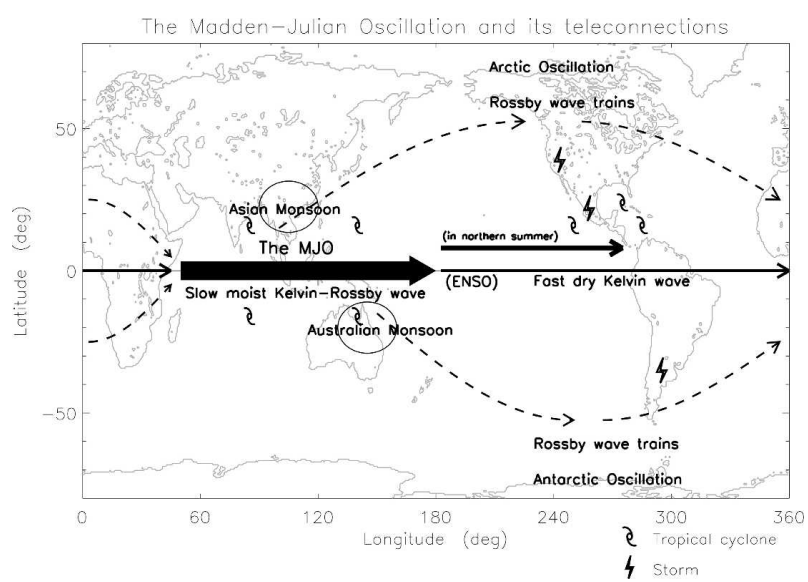

FIG. 1. Schematic depiction of the MJO and its teleconnections.

heat exchange (WISHE) feedback (Emanuel 1987; Neelin et al. 1987), or by providing strong equivalent linear mechanical damping making the MJO a highly viscous oscillation (Lin et al. 2005).

Recently, in preparation for the Intergovernmental Panel on Climate Change (IPCC) Fourth Assessment Report (AR4), more than a dozen international climate modeling centers conducted a comprehensive set of long-term simulations for both the twentieth century's climate and different climate change scenarios in the twenty-first century. Before conducting the extended simulations, many of the modeling centers applied an overhaul to their physical schemes to incorporate stateof-the-art research results. For example, almost all modeling centers have implemented prognostic cloud microphysics schemes to their models, some have added a moisture trigger to their deep convection schemes, and some now take into account convective momentum transport. Moreover, many modeling centers increased their models' horizontal and vertical resolutions and some conducted experiments with different resolutions. Some also did AMIP runs in addition to the standard coupled runs. Therefore, it is of interest to assess the MJO simulations in this new generation of climate models to look at the effects of the updated physical processes, higher resolution, and airsea coupling. Such an evaluation is also important for evaluating the general performance of the climate models used for climate change projections in the IPCC AR4.

In addition to the MJO, other convectively coupled equatorial waves mentioned above also strongly affect the tropical weather, for example, the occurrence of westerly wind burst events (e.g., Kiladis et al. 1994; Hartten 1996) and the formation of tropical cyclones (e.g., Dickinson and Molinari 2002; Goswami et al. 2003; Bessafi and Wheeler 2006). Because changes in tropical weather such as tropical cyclones are important aspects of climate change, it is relevant to check whether these convectively coupled equatorial waves are well simulated by the IPCC AR4 climate models along with the MJO.

The purpose of this study is to evaluate the tropical intraseasonal variability of convection in 14 IPCC AR4 climate models, with an emphasis on their MJO simulations. The following questions are addressed below.

1) How well do the IPCC AR4 models simulate the precipitation signals associated with convectively coupled equatorial waves, especially the MJO?

2) Is there any systematic dependence of model MJO simulations on the basic characteristics of convection schemes, such as closure assumption or model resolution?

3) Is there any common bias that is important for the simulation of the MJO?

The models and validation datasets used in this study are described in section 2. The diagnostic methods are described in section 3. Results are presented in section 4. A summary and discussion are given in section 5 .

\section{Models and validation datasets}

This analysis is based on $8 \mathrm{yr}$ of the climate of the twentieth century (20C3M) simulations from 14 coupled GCMs. Table 1 shows the model names and acronyms, their horizontal and vertical resolutions, and brief descriptions of their deep convection schemes. For each model we use $8 \mathrm{yr}$ of daily mean surface precipitation.

The model simulations are validated using multiple observational datasets. To bracket the uncertainties associated with precipitation measurements/retrievals, especially the well-known difference between infrared (IR) based retrievals and microwave-based retrievals (e.g., Yuter and Houze 2000), we use two different precipitation datasets: first, 8 yr (1997-2004) of daily Geostationary Operational Environmental Satellite (GOES) Precipitation Index (GPI; Janowiak and Arkin 1991) precipitation with a horizontal resolution of $2.5^{\circ}$ latitude by $2.5^{\circ}$ longitude, which is retrieved based on IR measurements from multiple geostationary satellites; and second, 8 yr (1997-2004) of daily Global Precipitation Climatology Project (GPCP) $1^{\circ}$ daily (1DD) precipitation (Huffman et al. 2001) with a horizontal resolution of $1^{\circ}$ latitude by $1^{\circ}$ longitude. These are IR-based GPI retrievals scaled by the monthly means of microwave-based Special Sensor Microwave Imager (SSM/I) retrievals. 


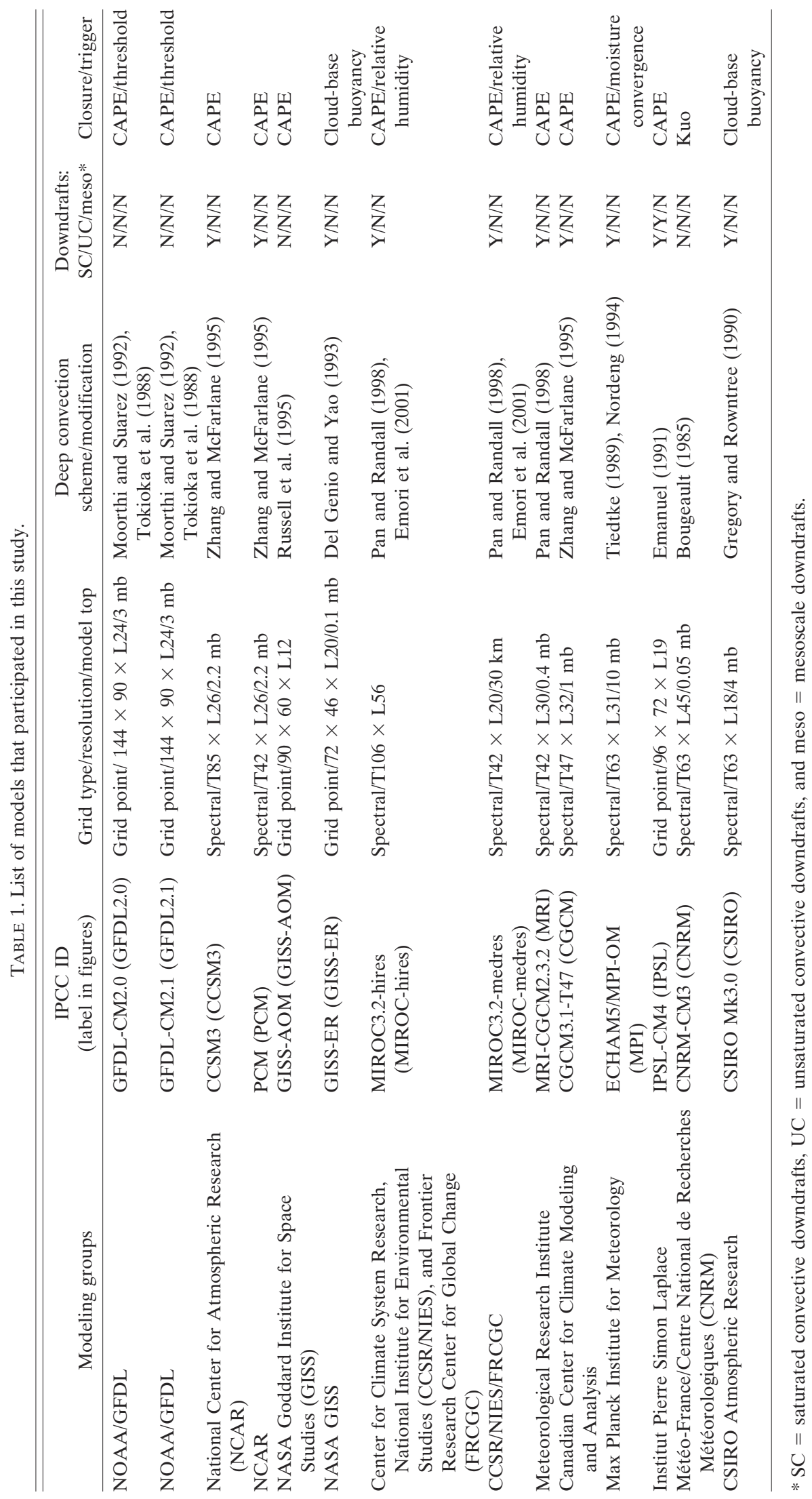




\section{Method}

\section{a. Identification of the dominant intraseasonal modes}

Through the space-time spectral analysis of outgoing longwave radiation (OLR), Takayabu (1994) and WK demonstrated that a significant portion of tropical cloudiness is organized in waves corresponding to the normal modes of the linear shallow water system isolated by Matsuno (1966). In WK, these spectra represent the power remaining in the symmetric and antisymmetric components of OLR about the equator after dividing raw wavenumber-frequency power spectra by an estimate of the background power spectrum. Peaks standing above the background correspond to the Kelvin, $n=1$ equatorial Rossby (ER), mixed Rossbygravity (MRG), $n=0$ eastward inertio-gravity (EIG), and $n=1$ westward inertio-gravity (WIG) and $n=2$ WIG waves. It was found that the dispersion curves that best match the wavenumber-frequency characteristics of these waves have surprisingly shallow equivalent depths in the range of roughly $25 \mathrm{~m}$, which is about an order of magnitude smaller than that expected for a free wave with a similar vertical wavelength twice the depth of the troposphere (e.g., Salby and Garcia 1987; Wheeler et al. 2000).

Using the methodology of WK, space-time spectra of daily tropical precipitation were obtained for the $8 \mathrm{yr}$ of model data used in this study and compared with the results of $8 \mathrm{yr}$ of observed precipitation estimates from the GPI and 1DD datasets. We will briefly outline this procedure here, and refer the reader to WK for further details.

The model and validation precipitation data were first interpolated to a zonal resolution of $5^{\circ}$ longitude with the latitudinal resolution varying from model to model (Table 1). As demonstrated by WK, the structure of convectively coupled equatorial waves is either symmetric or antisymmetric about the equator, in accordance with shallow water theory. A gridded field $D$ that is a function of latitude, $\varphi$, can be written as $D(\varphi)=$ $\operatorname{DA}(\varphi)+\operatorname{DS}(\varphi)$, where $\operatorname{DA}(\varphi)=[D(\varphi)-D(-\varphi)] / 2$ is the antisymmetric component, and $\operatorname{DS}(\varphi)=[D(\varphi)+$ $D(-\varphi)] / 2$ is the symmetric component. We first decomposed the precipitation into its antisymmetric and symmetric components, averaged these from $15^{\circ} \mathrm{N}$ to $15^{\circ} \mathrm{S}$, and computed spectra of the averaged values. Although this last step is mathematically different from the procedure used in WK, in which spectra of the symmetric/ antisymmetric components were computed separately for each latitude before being averaged together, for the scales of interest here the results and interpretation are the same.
To reduce noise, the space-time spectra were calculated as in WK for successive overlapping segments of data and then averaged, here 128 days long with 78 days of overlap between each segment. Complex Fourier coefficients are first obtained in zonal planetary wavenumber space, which are then subjected to a further complex FFT to obtain the wavenumber-frequency spectrum for the symmetric and antisymmetric components of precipitation about the equator.

An estimate of the "background" space-time spectrum is obtained for each dataset by averaging the power of the symmetric and antisymmetric spectra and smoothing this by successive passes of a 1-2-1 filter in frequency and wavenumber (see WK). The raw spectra are then divided by this background to obtain an estimate of the signal standing above the background noise. In WK, power at 1.1 times the background or greater was deemed significant, based on a crude estimate of the degrees of freedom involved. In reality, a true estimate of the degrees of freedom is difficult to obtain due to the complications of simultaneous autocorrelation in both space and time. Here, since the datasets used are significantly shorter than those used in WK ( 8 versus $18 \mathrm{yr}$ ), we assume the signal is significant if it stands at 1.2 times (or 20\% above) the background. It should be emphasized that, while this is only a rough estimate of the true "significance" of the signals, the intent is to simply identify those modes that might represent signals in rainfall standing above a simple red noise continuum that would presumably prevail if rainfall were not organized by disturbances on the large scale.

\section{b. Isolating the Kelvin, ER, MRG, EIG, and WIG modes}

In this paper, the definitions of Kelvin, ER, MRG, EIG, and WIG modes are as in WK (see their Fig. 6), and were isolated using the same method: each mode was isolated by filtering in the wavenumber-frequency domain (see Fig. 6 of WK for the defined regions of filtering for each wave), and the corresponding time series were obtained by an inverse space-time Fourier transform.

\section{c. Isolating the MJO mode}

The MJO is defined as significant rainfall variability in eastward wavenumbers 1-6 and in the period range of 30-70 days. To isolate the MJO mode, we first used an inverse space-time Fourier transform to get the time series of the eastward wavenumber 1-6 component, which includes all available frequencies. Then these 
time series were filtered using a 365-point 30-70-day Lanczos filter (Duchan 1979), whose response function is shown in Fig. 2. Because the Lanczos filter is nonrecursive, 182 days of data were lost at each end of the time series (364 days in total). The resultant eastward wavenumber $1-6,30-70$-day anomaly is hereafter referred to as the MJO anomaly.

The variance of the MJO anomaly was also compared with the variance of its westward counterpart, that is, the westward wavenumber 1-6, 30-70-day anomaly, which was isolated using the same method as above.

It is important to note that we only focus on the $\mathrm{MJO}$, which propagates eastward and amplifies to a seasonal maximum on the equator in boreal winter and spring, when climatological convection and warm SST cross the equator (Salby and Hendon 1994; Zhang and Dong 2004; Wheeler and Hendon 2004). Analysis of the boreal summer intraseasonal oscillation (BSIO; e.g., Yasunari 1979; Knutson et al. 1986; Kemball-Cook and Wang 2001; Lawrence and Webster 2002; Straub and Kiladis 2003; Waliser et al. 2003c, among many others), which has a major northward propagating component and has its maximum variance in the Asian monsoon region, is beyond the scope of this study.

\section{Results}

\section{a. Climatological precipitation in the equatorial belt}

Previous observational studies indicate that the intraseasonal variance of convection is highly correlated with time-mean convective intensity (e.g., WK; Hendon et al. 1999). Therefore, we first look at the 8-yr timemean precipitation along the equatorial belt, especially over the Indo-Pacific warm pool region, where most of the convectively coupled equatorial waves have the

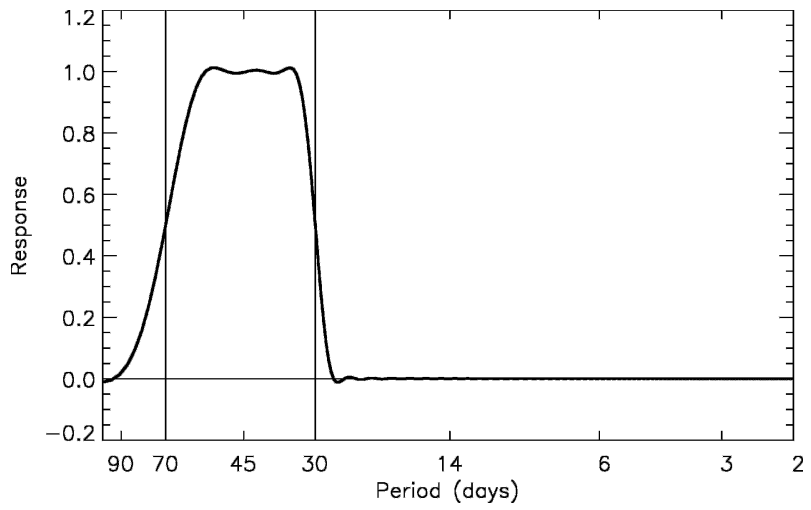

FIG. 2. Response function of the 365-point Lanczos filter used in this study.
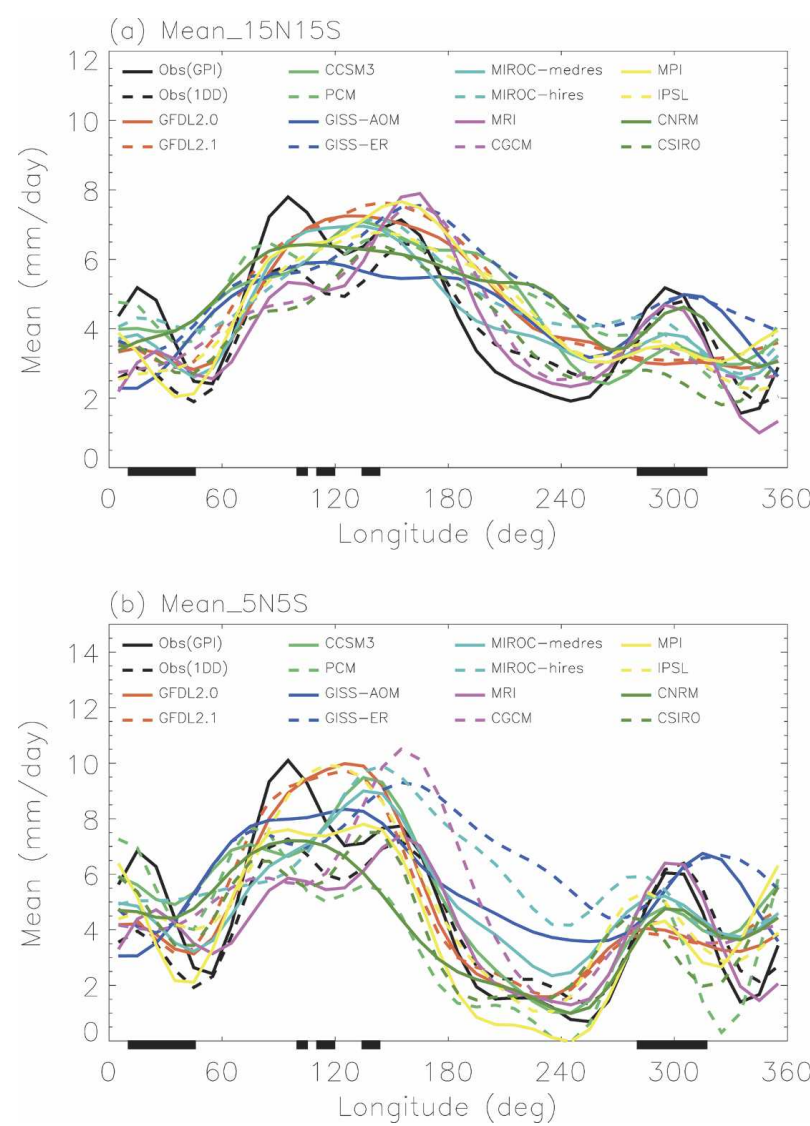

Fig. 3. Annual mean precipitation along the equatorial belt averaged between (a) $15^{\circ} \mathrm{N}-15^{\circ} \mathrm{S}$ and (b) $5^{\circ} \mathrm{N}-5^{\circ} \mathrm{S}$ for two observational datasets and 14 models.

largest variance (WK). Figure 3a shows the annual mean precipitation versus longitude averaged between $15^{\circ} \mathrm{N}$ and $15^{\circ} \mathrm{S}$. To focus on the large-scale features, we smoothed the data zonally to retain only zonal wavenumbers 0-6. All models reproduce the basic feature of observed precipitation, with the primary maximum over the Indo-Pacific warm pool region, and two secondary maxima over Central/South America and Africa. The magnitude of the precipitation over the warm pool in all models is close to that in the observations. Within the warm pool region, several models (GFDLCM2.0, GFDL-CM2.1, CCSM3, GISS-AOM, CNRMCM3, MIROC3.2-medres) do not reproduce the local minimum of precipitation over the Maritime Continent, and there is a tendency for the models to produce more precipitation over the western Pacific than over the eastern Indian Ocean, which is a feature in 1DD data but not in GPI data. Outside the warm pool region, two notable common biases are excessive rainfall over the eastern Pacific in most models and insufficient rainfall over Central/South America in many models. 
When the precipitation is averaged over a narrower belt closer to the equator between $5^{\circ} \mathrm{N}$ and $5^{\circ} \mathrm{S}$, models show a larger scatter in their performance, especially over the western Pacific (Fig. 3b). Several models (CGCM3.1-T47, MIROC3.2-medres, MIROC3.2-hires, CCSM3, and GISS-ER) produce much greater precipitation than is found in the observations, and produce much larger precipitation over the western Pacific than over the eastern Indian Ocean, a feature that is not observed. On the other hand, several other models (PCM, CNRM-CM3) show too weak precipitation over the western Pacific, which is significantly smaller than their corresponding $15^{\circ} \mathrm{N}-15^{\circ} \mathrm{S}$ average (Fig. 3a). This is caused by the prominent double-ITCZ pattern in their horizontal distributions (not shown). Outside the warm pool region, most models (except GISS-AOM, GISS-ER, and MIROC3.2-hires) reproduce the precipitation minimum over the eastern Pacific trade wind cumulus region reasonably well, but there is a large scatter over Africa and the Atlantic Ocean.

In short, the climatological precipitation over the Indo-Pacific warm pool is reasonably simulated by IPCC AR4 climate models, except that several models (PCM, CNRM-CM3, and MRI-CGCM2.3.2) produce too weak precipitation on the equator in the western Pacific due to their double-ITCZ problem.

\section{b. Total intraseasonal (2-128 day) variance and raw space-time spectra}

Figures $4 \mathrm{a}$ and $4 \mathrm{~b}$ show the total variance of the 2-128-day precipitation anomaly along the equator averaged between $15^{\circ} \mathrm{N}-15^{\circ} \mathrm{S}$ and $5^{\circ} \mathrm{N}-5^{\circ} \mathrm{S}$, respectively. Despite their reasonable annual mean precipitation over the Indo-Pacific warm pool, the total intraseasonal variance in most models is smaller than in the observations. There is a tendency for the models to have larger variance over the western Pacific than over the Indian Ocean, which is consistent with their tendency to have larger annual mean precipitation over the western $\mathrm{Pa}-$ cific (Fig. 3), and agrees with the result of the atmospheric GCM analysis of Waliser et al. (2003d) that models did a very poor job with the means and variances over the Indian Ocean. The variance in several models (e.g., ECHAM5/MPI-OM, MIROC3.2-medres, and CGCM3.1-T47) approaches the observed value on the equator over the western Pacific (Fig. 4b).

The symmetric space-time spectra of the two observational rainfall datasets, GPI and 1DD, are shown in Fig. 5a, and Fig. 5b where, as in WK, the plotted contours are the logarithm of the power. These spectra are nearly identical to each other, and also very similar in shape to those obtained by WK, even though WK used
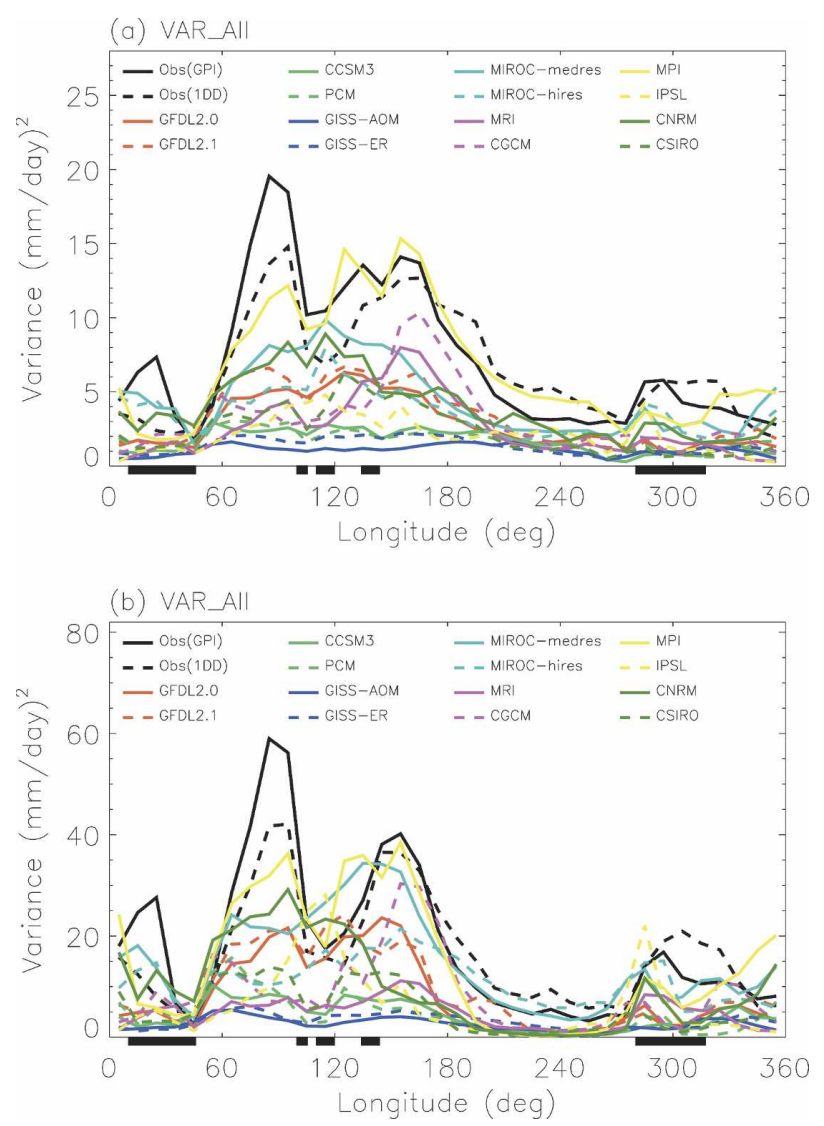

FIG. 4. Variance of the 2-128-day precipitation anomaly along the equator averaged between (a) $15^{\circ} \mathrm{N}-15^{\circ} \mathrm{S}$ and (b) $5^{\circ} \mathrm{N}-5^{\circ} \mathrm{S}$.

OLR instead of the blend of precipitation estimates composing the GPI and 1DD datasets. As in WK, the spectra are very red in time and space, with most power at the largest spatial scales and lowest frequencies. Despite this redness, distinct spectral peaks and gaps are evident even in these raw spectra. One obvious feature is the dominance of eastward over westward power at low wavenumbers and frequencies, a signal corresponding to the MJO. Other peaks also correspond to known equatorial wave modes, and will be discussed further below.

The remainder of Fig. 5 displays the corresponding spectra from the various models examined for this study, using identical contour intervals and shading as in Figs. 5a and 5b (recall that these spectra are calculated for identical daily and $5^{\circ}$ horizontal resolutions). There are two important features in the model spectra. First, all models except the MIROC3.2-hires and MIROC3.2-medres models have much less power than observed at periods shorter than 6 days, while many of the models (e.g., CCSM3, PCM, GISS-AOM, GISSER, MRI-CGCM2.3.2, CGCM3.1-T47, IPSL-CM4, and 
(a) GPI

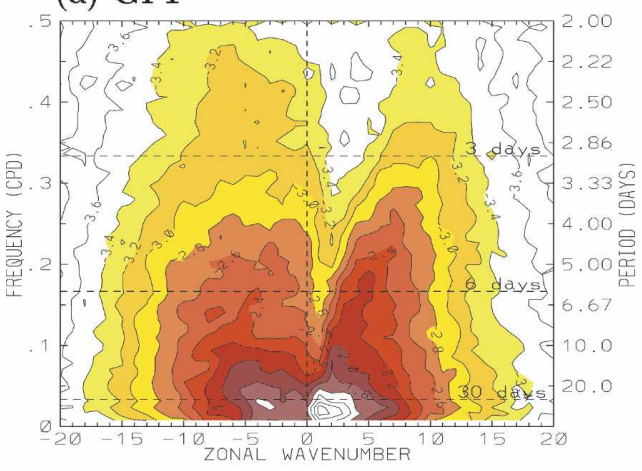

(c) GFDL2.0

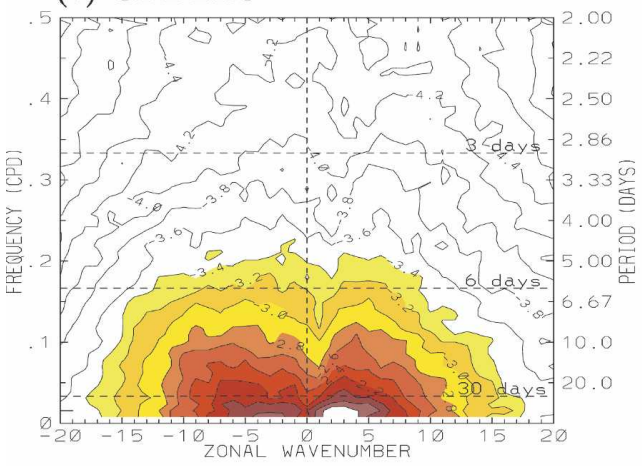

(e) CCSM3

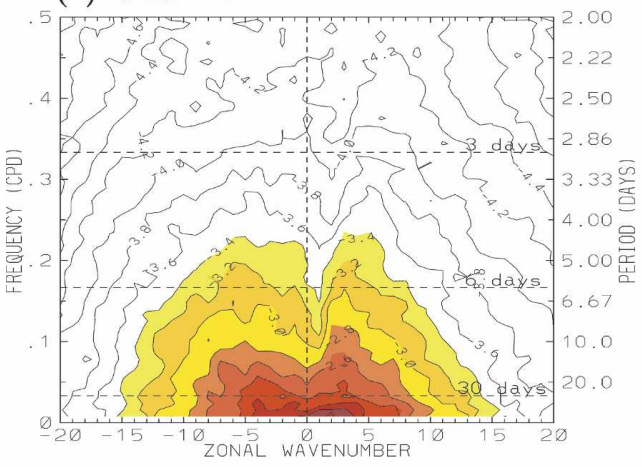

(g) GISS-AOM

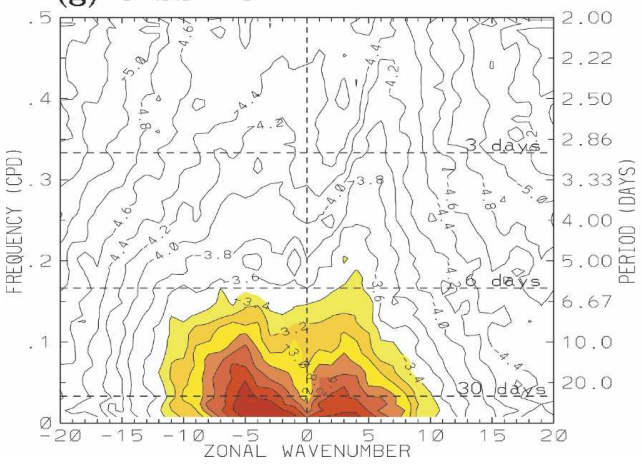

(b) 1DD

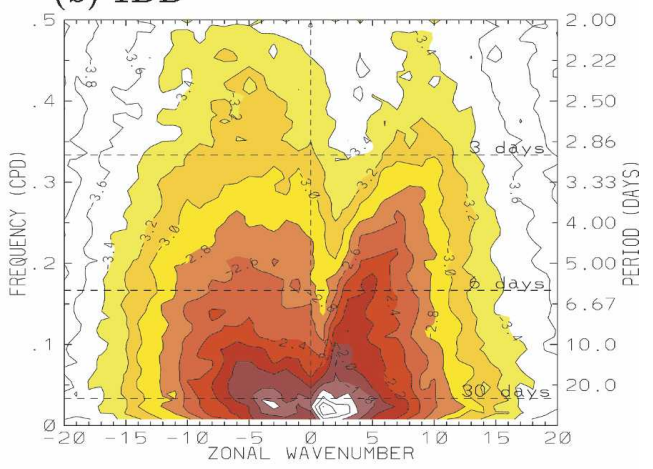

(d) GFDL2.1

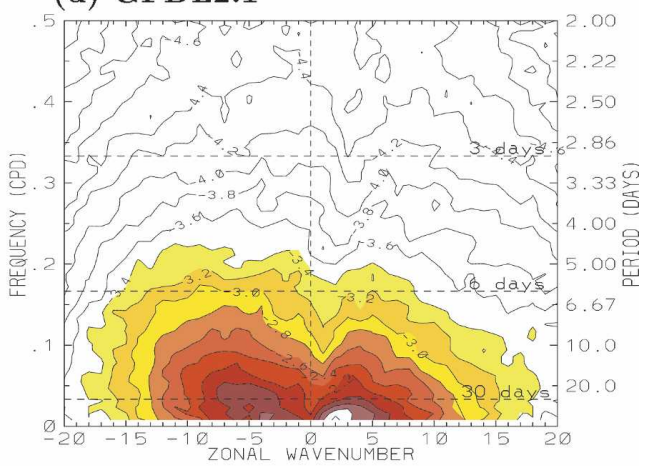

(f) PCM

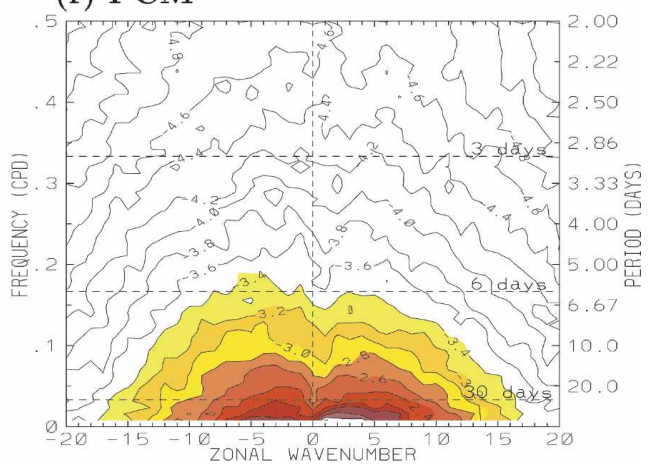

(h) GISS-ER

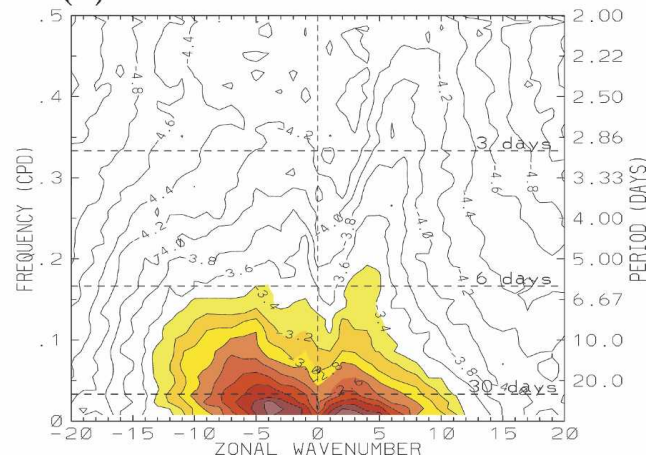

FIG. 5. Space-time spectrum of $15^{\circ} \mathrm{N}-15^{\circ} \mathrm{S}$ symmetric component of precipitation. Frequency spectral width is $1 / 128 \mathrm{cpd}$. 
(i) MIROC-medres

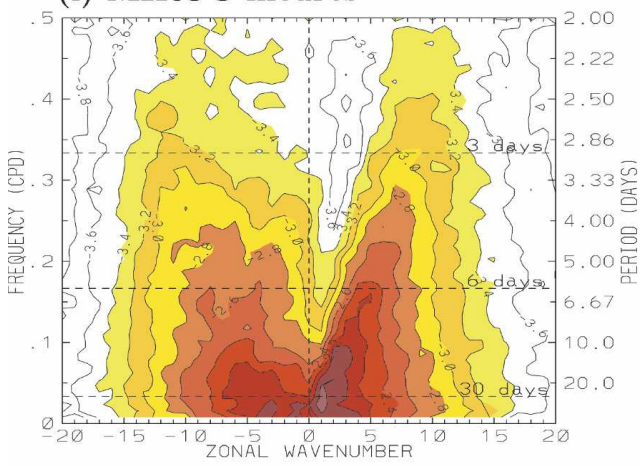

(k) MRI

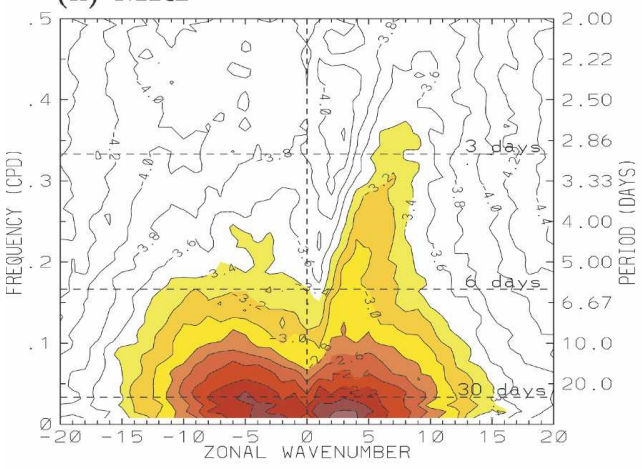

(m) MPI

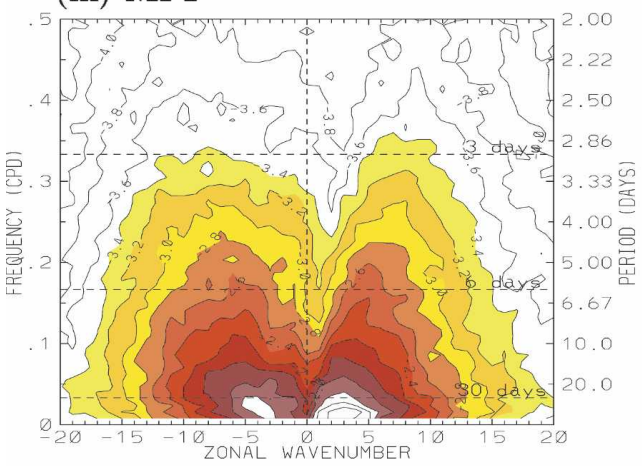

(o) CNRM

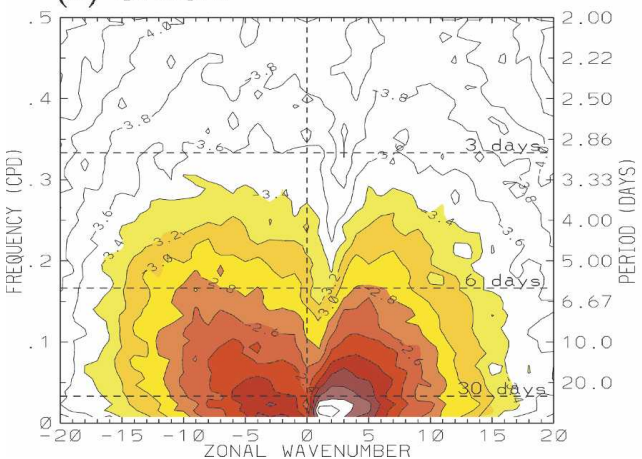

(j) MIROC-hires

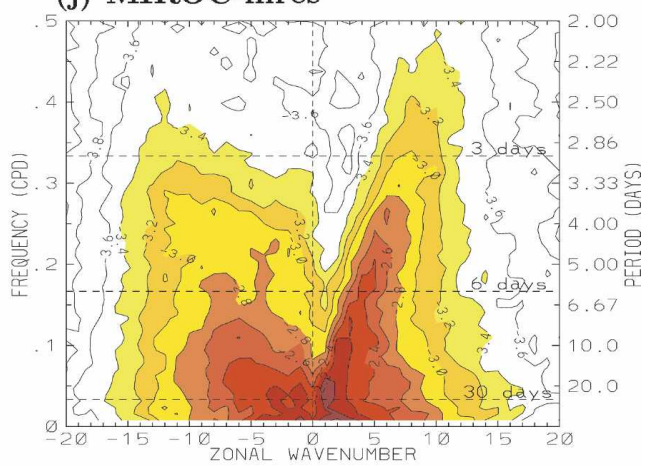

(1) CGCM

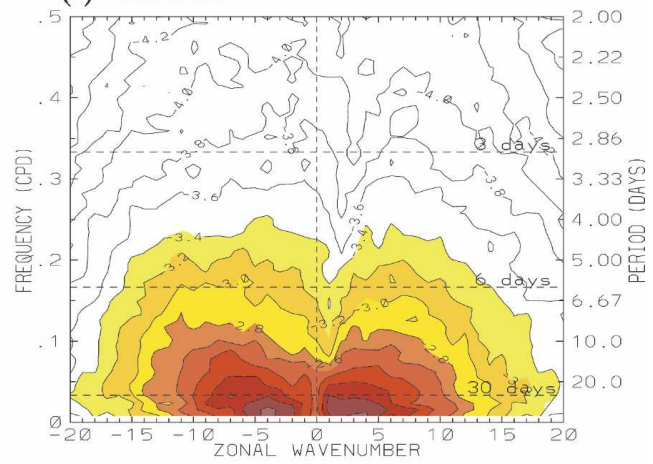

(n) IPSL

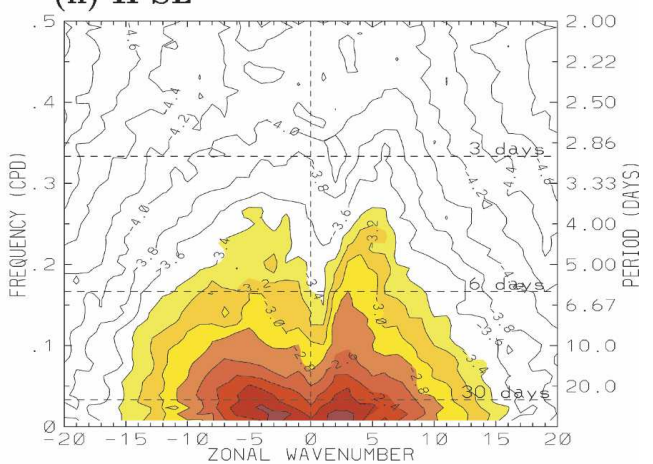

(p) CSIRO

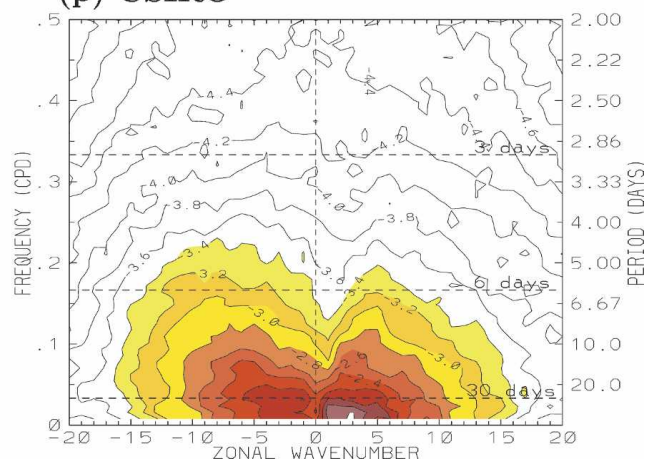

FIG. 5. (Continued) 
(a) GPI

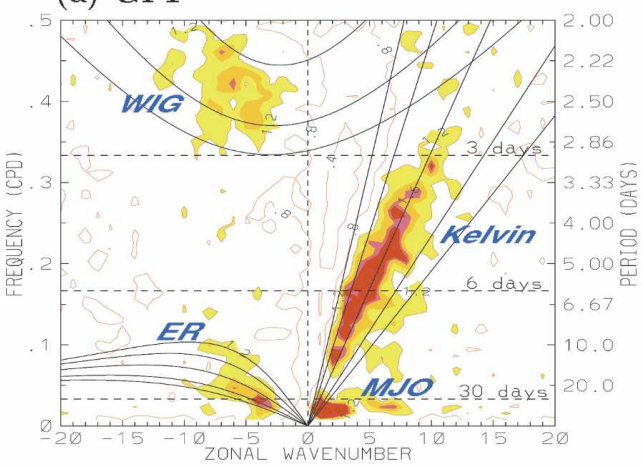

(c) GFDL2.0

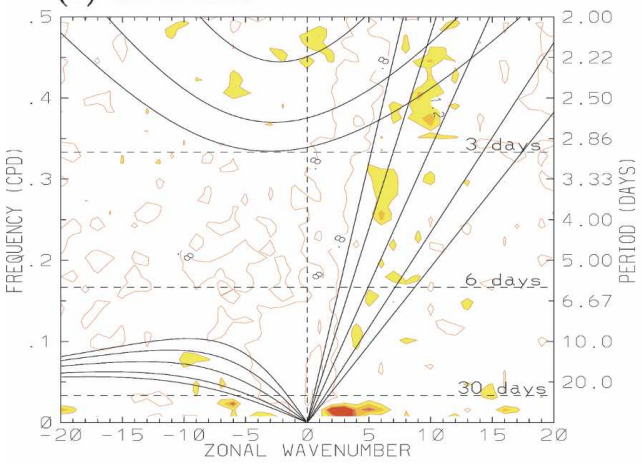

(e) CCSM3

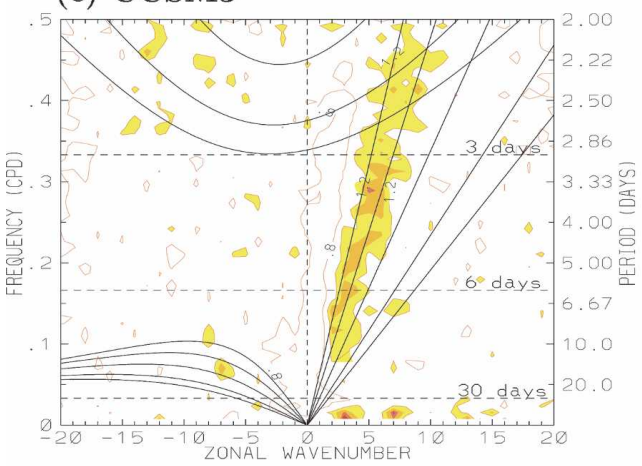

(g) GISS-AOM

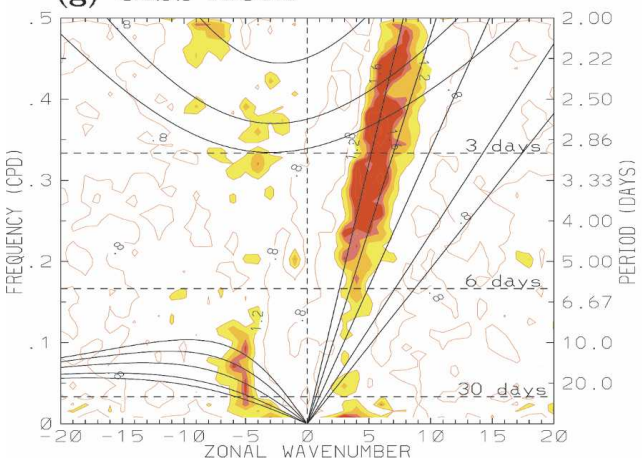

(b) 1DD

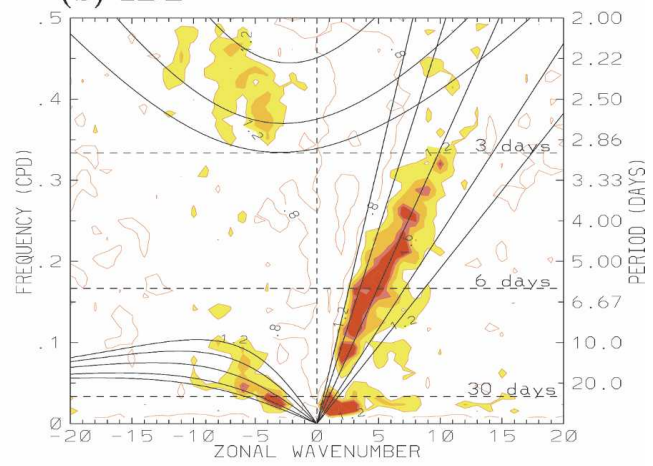

(d) GFDL2.1

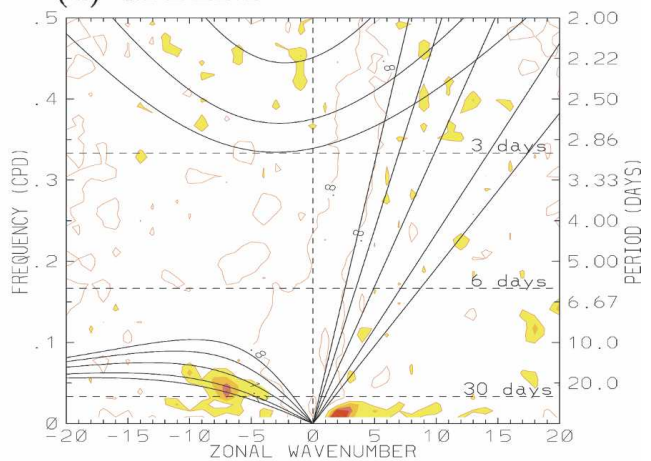

(f) PCM

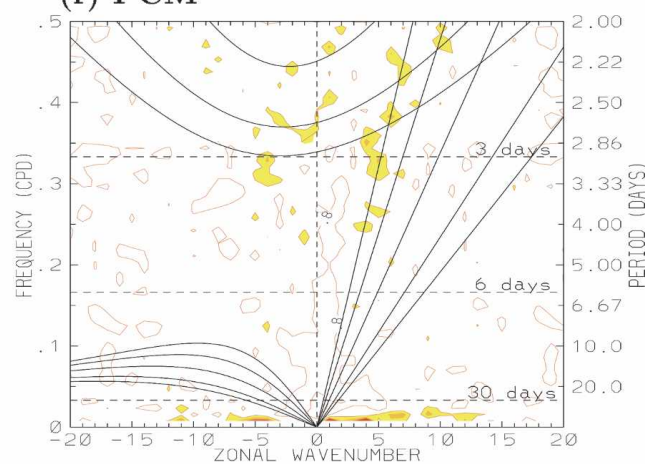

(h) GISS-ER

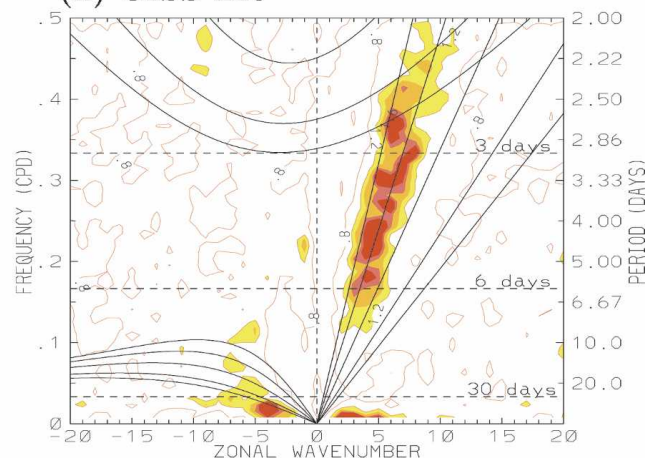

FIG. 6. Space-time spectrum of the $15^{\circ} \mathrm{N}-15^{\circ} \mathrm{S}$ symmetric component of precipitation divided by the background spectrum. Superimposed are the dispersion curves of the odd meridional mode numbered equatorial waves for the five equivalent depths of $8,12,25,50$, and $90 \mathrm{~m}$. Frequency spectral width is $1 / 128 \mathrm{cpd}$. 
(i) MIROC-medres

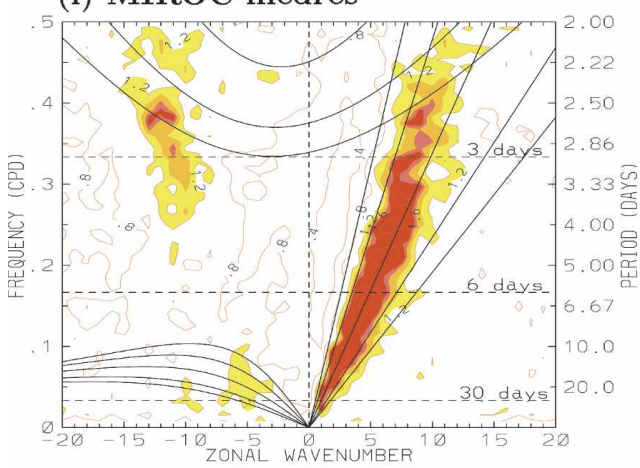

(k) MRI

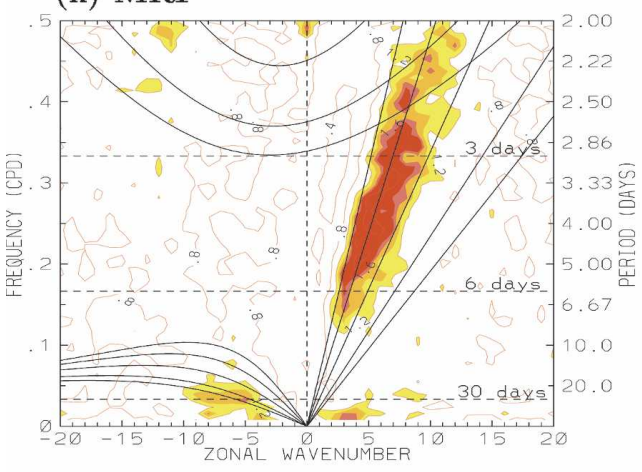

(m) MPI

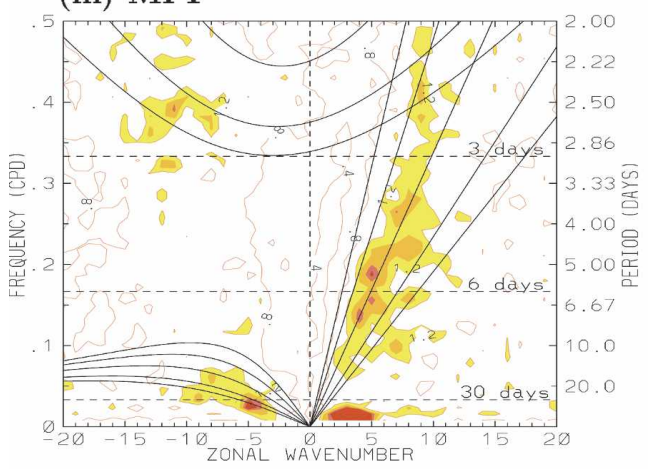

(o) CNRM

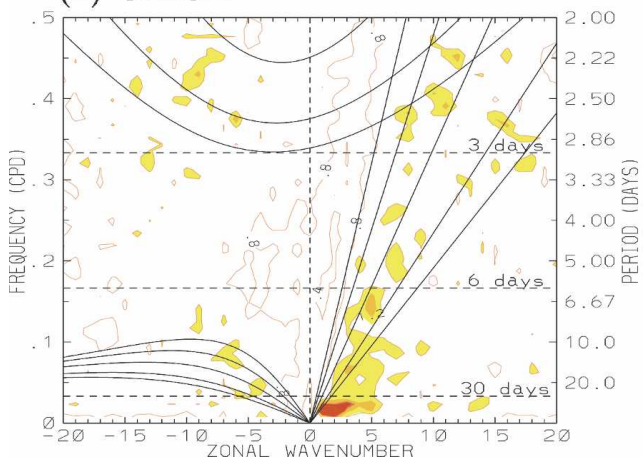

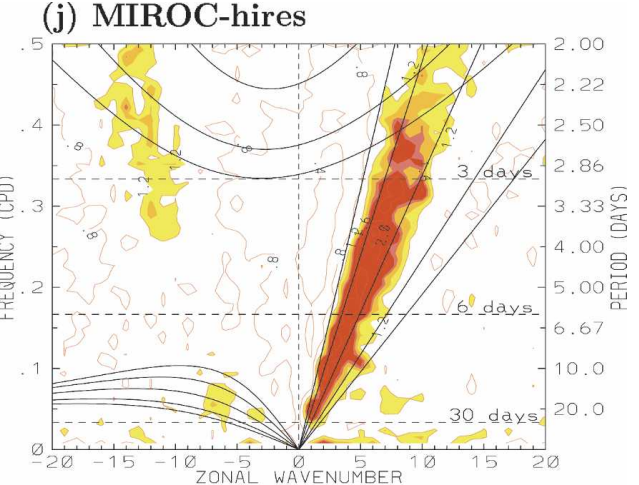

(1) CGCM

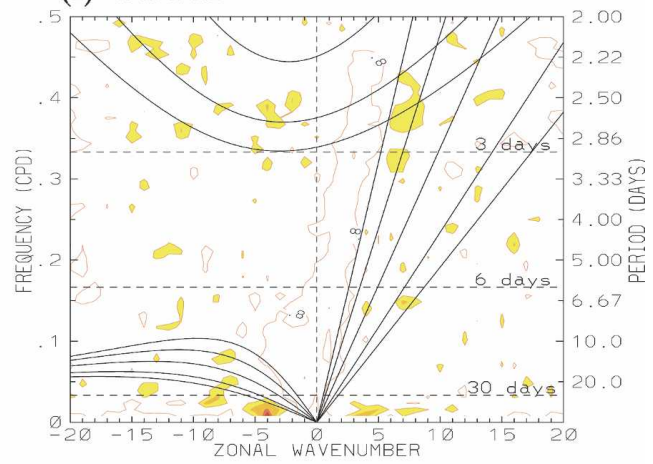

(n) IPSL

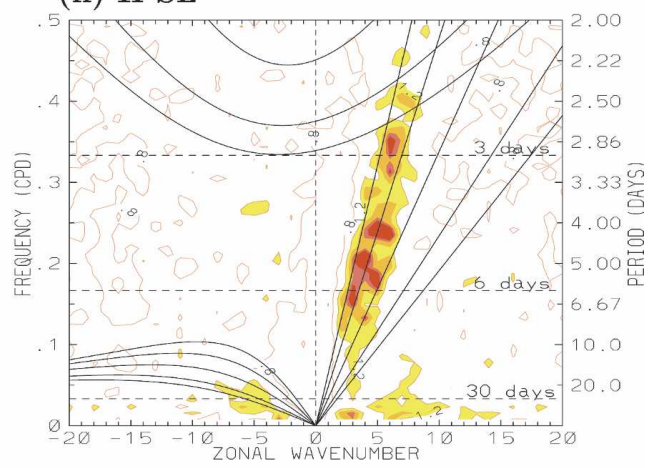

(p) CSIRO

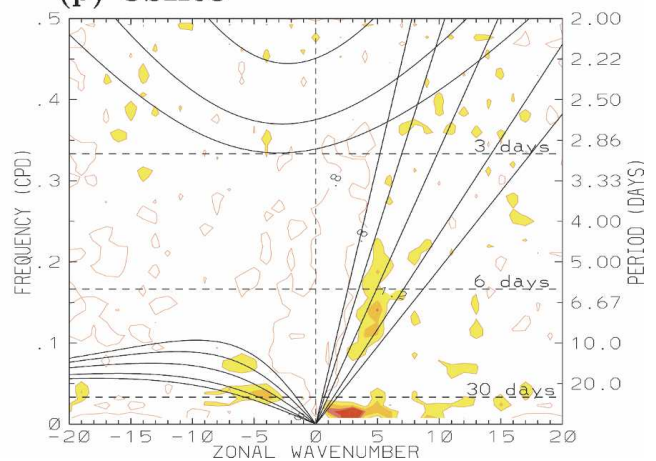

FIG. 6. (Continued) 
(a) GPI

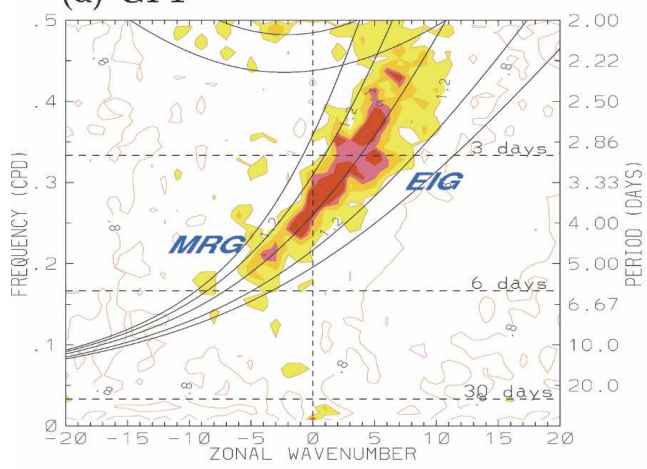

(c) GFDL2.0

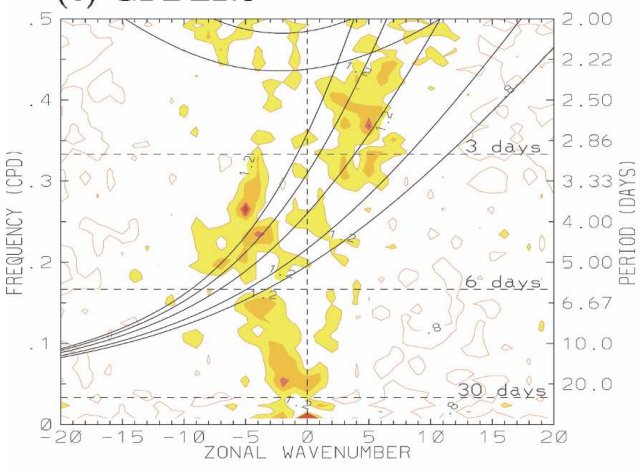

(e) CCSM3

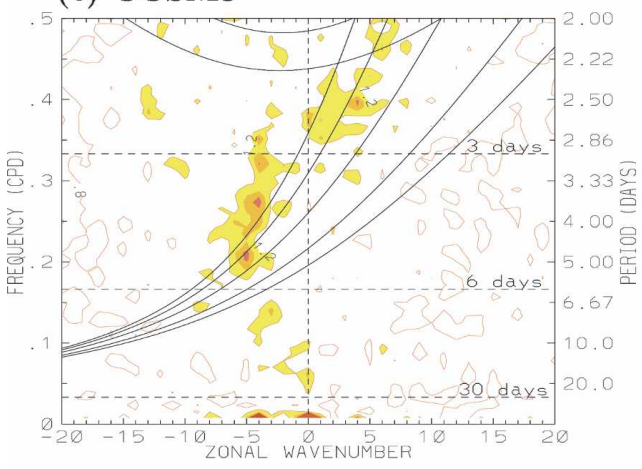

(g) GISS-AOM

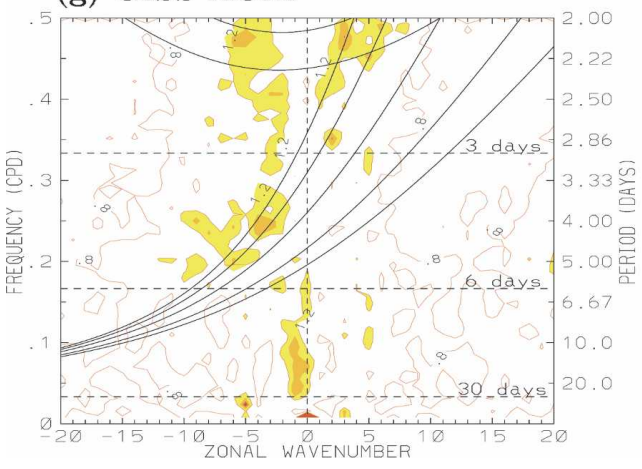

(b) 1DD

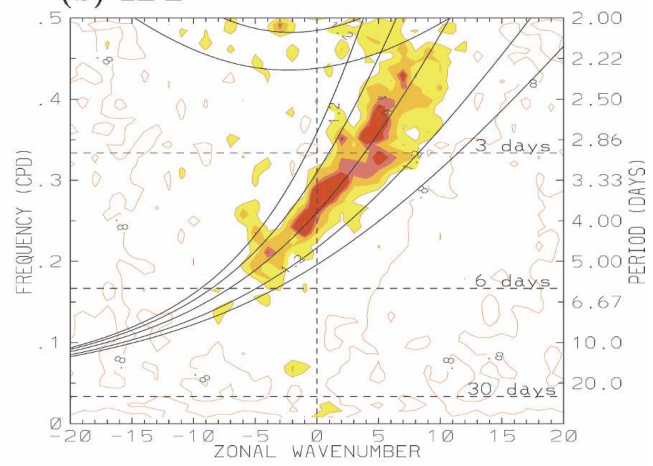

(d) GFDL2.1

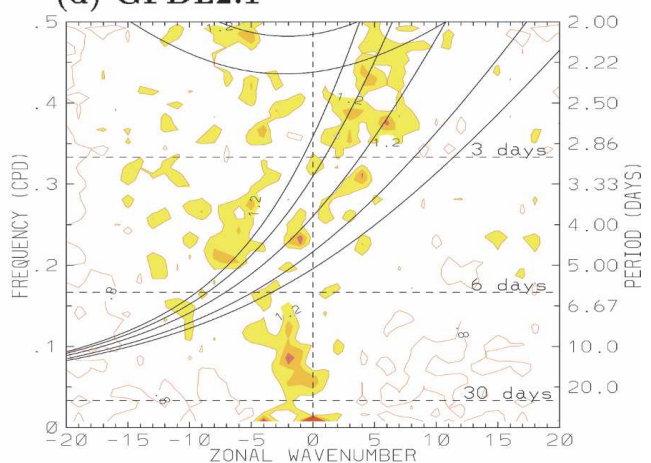

(f) PCM

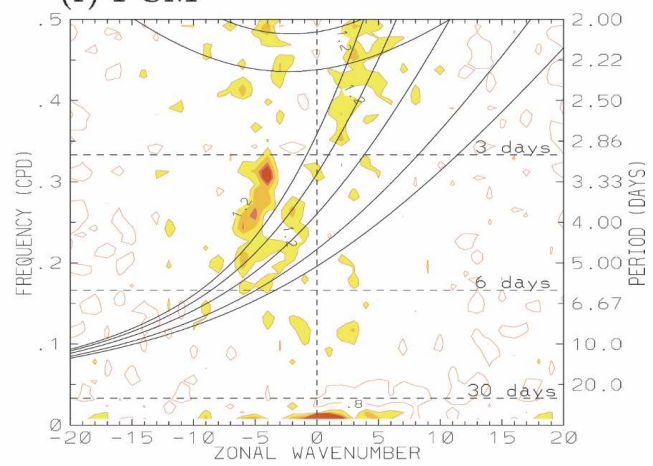

(h) GISS-ER

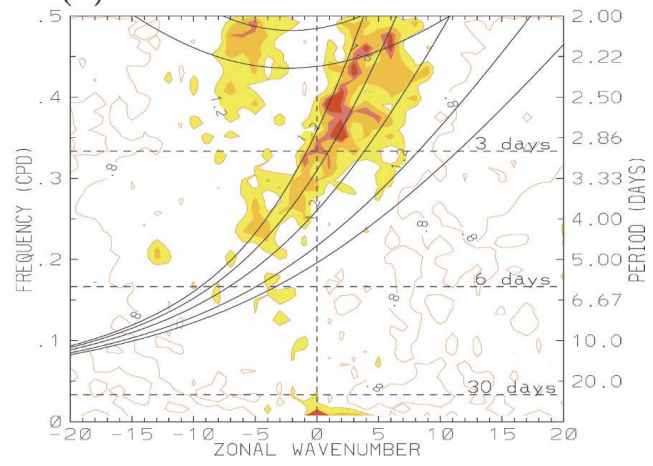

FIG. 7. As in Fig. 6 except for the $15^{\circ} \mathrm{N}-15^{\circ} \mathrm{S}$ antisymmetric component of precipitation. 
(i) MIROC-medres

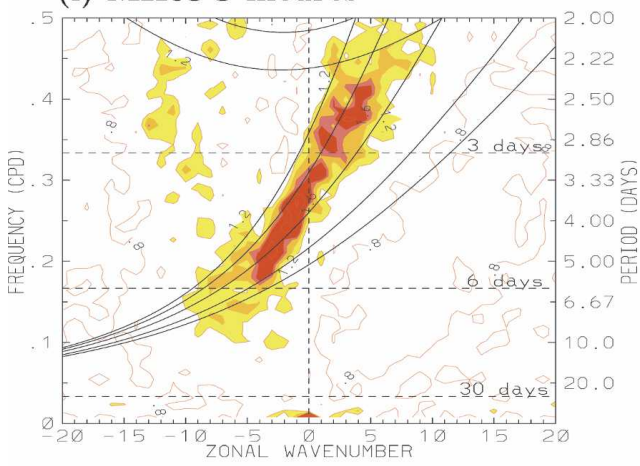

(k) MRI

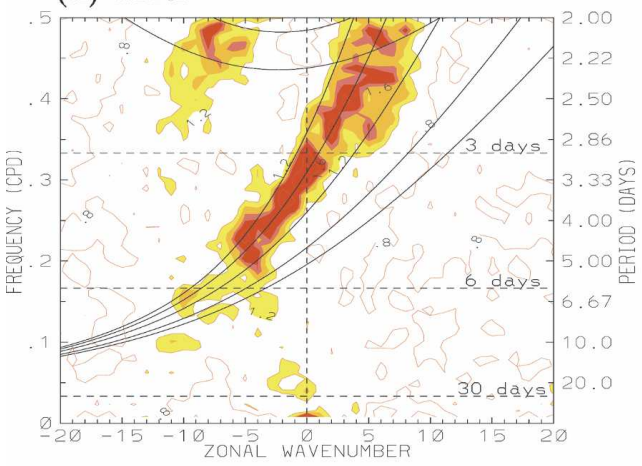

(m) MPI

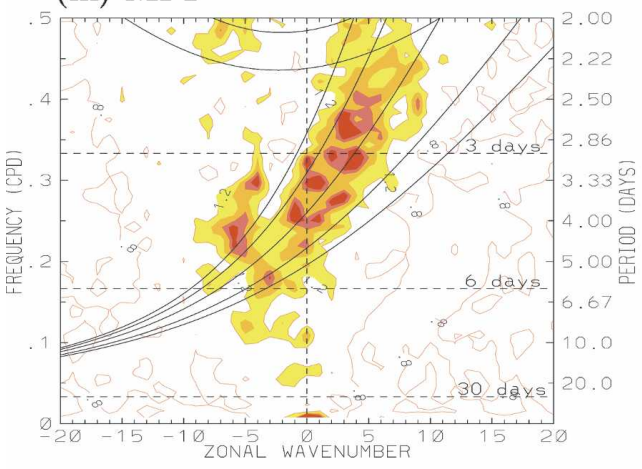

(o) CNRM

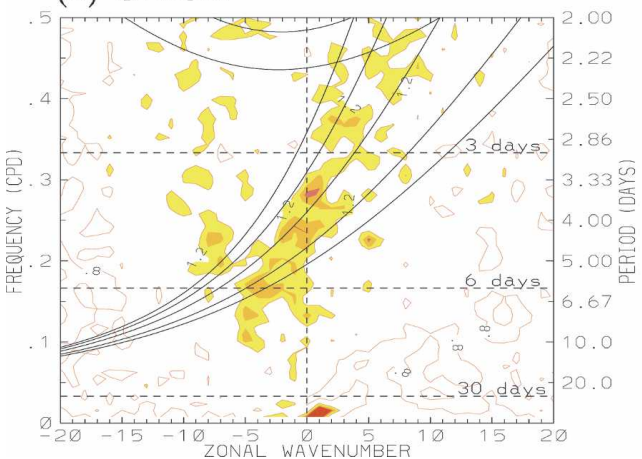

(j) MIROC-hires

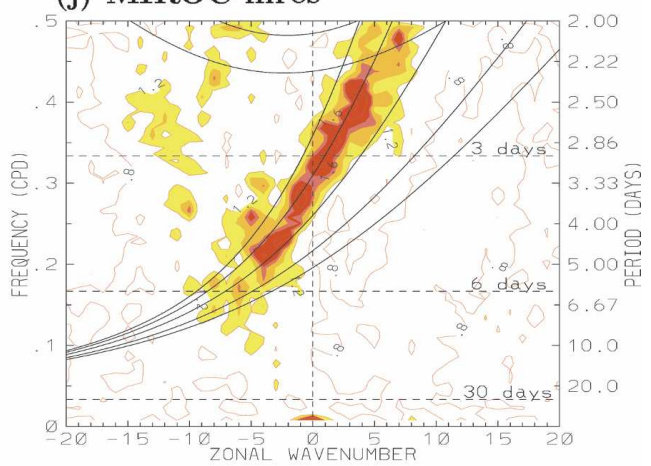

(1) CGCM

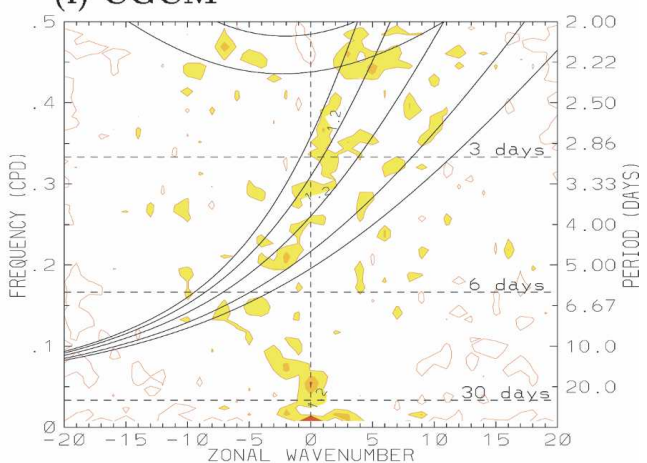

(n) IPSL

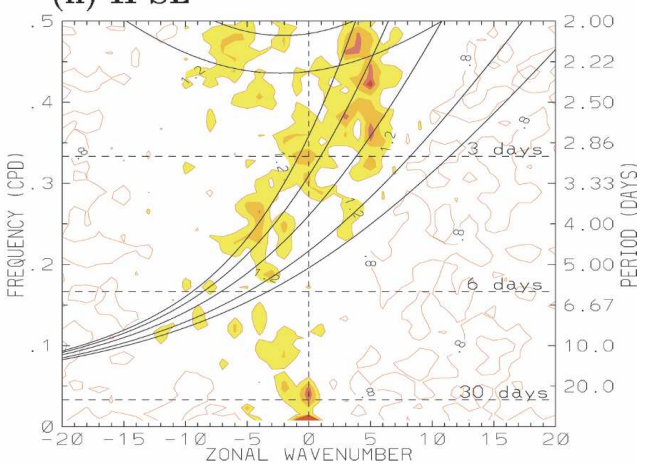

(p) CSIRO

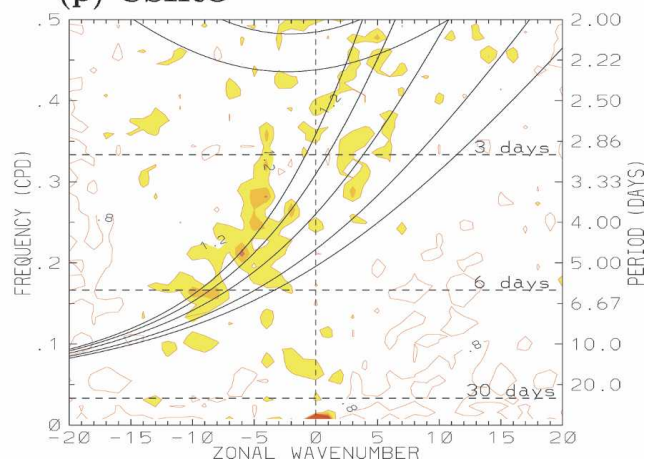

FIG. 7. (Continued) 
CSIRO Mk3.0) also have less power than observed at periods longer than 6 days. These are consistent with the too weak total intraseasonal (2-128 days) variances in these models (Fig. 4). Second, in some model spectra (e.g., GISS-ER) westward over eastward power is too strong at MJO time scales, while in others (e.g., CCSM, PCM1, and GISS-AOM) the power is more evenly distributed. If the eastward signals and the westward signals are coherent with each other, they would form more standing oscillations rather than the predominance of eastward propagations seen in the observations. The characteristics of the raw antisymmetric spectra, in terms of total power and redness, are generally similar to Fig. 6 and so will not be shown here.

In summary, the total intraseasonal (2-128 day) variance of precipitation in most models is smaller than in the observations. The space-time spectra of most models have much less power than is observed, especially at periods shorter than 6 days. In some model spectra westward over eastward power is too strong at MJO time scales, while in others the power is more evenly distributed.

\section{c. Dominant intraseasonal modes}

Figures 6 and 7 show the results of dividing the symmetric and antisymmetric raw spectra by the estimates of their background spectra. This normalization procedure removes a large portion of the systematic biases within the various models and observed datasets in Fig. 5 , more clearly displaying the model disturbances with respect to their own climatological variance at each scale.

Signals of the Kelvin, ER, and WIG waves are readily identified in the observational symmetric spectra (Figs. 6a and 6b), along with the MRG and EIG waves in the antisymmetric spectra (Figs. 7a and 7b). The MJO also appears as a prominent signal, especially in the symmetric spectra. Dispersion curves of the shallow water modes are also shown on all spectra, corresponding to equivalent depths of $8,12,25,50$, and $90 \mathrm{~m}$. As in the OLR spectra of WK, all of the observed spectral peaks corresponding to shallow water modes best match an equivalent depth of around $25 \mathrm{~m}$ in the observational rainfall data.

About half of the models appear to have signals of convectively coupled equatorial waves, with Kelvin and MRG-EIG waves especially prominent. This is an extremely encouraging finding, because previous versions of some of these same models showed very little in the way of signal corresponding to these modes (Wheeler 1998). Since it is thought that the interplay between convectively coupled waves is important to the low- frequency variability of the tropical atmosphere (e.g., Majda and Biello 2004, 2005; Moncrieff 2004; Kiladis et al. 2005), the existence of a wide variety of observed equatorial waves in these models opens the possibility that such scale interactions could be represented with current parameterization schemes. However, it turns out that the majority of the models with good signals (e.g., GISS-ER, MIROC3.2-hires, MRI-CGCM2.3.2, and IPSL-CM4) have too fast phase speeds and scale these disturbances to equivalent depths of around $50 \mathrm{~m}$, with some scaling closer to $90 \mathrm{~m}$ (e.g., GISS-AOM, CCSM). Only one model, the ECHAM5/MPI-OM, has signals that scale closely to the observed $25 \mathrm{~m}$ for all modes. Interestingly, this scaling is consistent within a given model across modes; that is, all modes scale similarly to a certain equivalent depth within a given pair of symmetric and antisymmetric spectra. This is indicative of similar physical processes linking the convection and large-scale disturbances within each model.

The spectral signature of the MJO is also represented in many of the models with varying realism. In observations, there is a clear distinction between eastward power in the MJO range and westward power associated with ER waves. Some of the models (GFDLCM2.1, GISS-AOM, MRI-CGCM2.3.2, and ECHAM5/ MPI-OM) represent this distinction to some extent, with the eastward power lying at a constant frequency across all wavenumbers and the westward power lying more along the ER dispersion curves, or at least at a somewhat higher frequency. In other models (PCM, GISS-ER, and CGCM3.1-T47) the westward power is confined more to the lower frequencies with $>30$ day periods, which would represent a standing oscillation if coherent with the eastward portion of the signal. This is confirmed by further analysis below in sections $4 \mathrm{c}$ and 4e. Still other models have eastward but little westward power (CCSM, CNRM-CM3), while the MIROC3.2medres and MIROC3.2-hires models have prominent Kelvin and ER signals but little in the way of power in the MJO range.

When a model displays signals of a certain wave mode in Figs. 6 and 7, it means that the variance of that wave mode stands out above the background spectra (i.e., a high signal-to-noise ratio), but the absolute value of the variance of that wave mode may not be large. Therefore, it is of interest to look further at the absolute values of the variance of each wave mode. Figures 8a-e, respectively, show the variances of the Kelvin, ER, MRG, EIG, and WIG modes along the equator averaged between $15^{\circ} \mathrm{N}$ and $15^{\circ} \mathrm{S}$. For the Kelvin mode (Fig. 8a), all models show too weak variance except that MIROC3.2-medres and MIROC3.2-hires show strong 

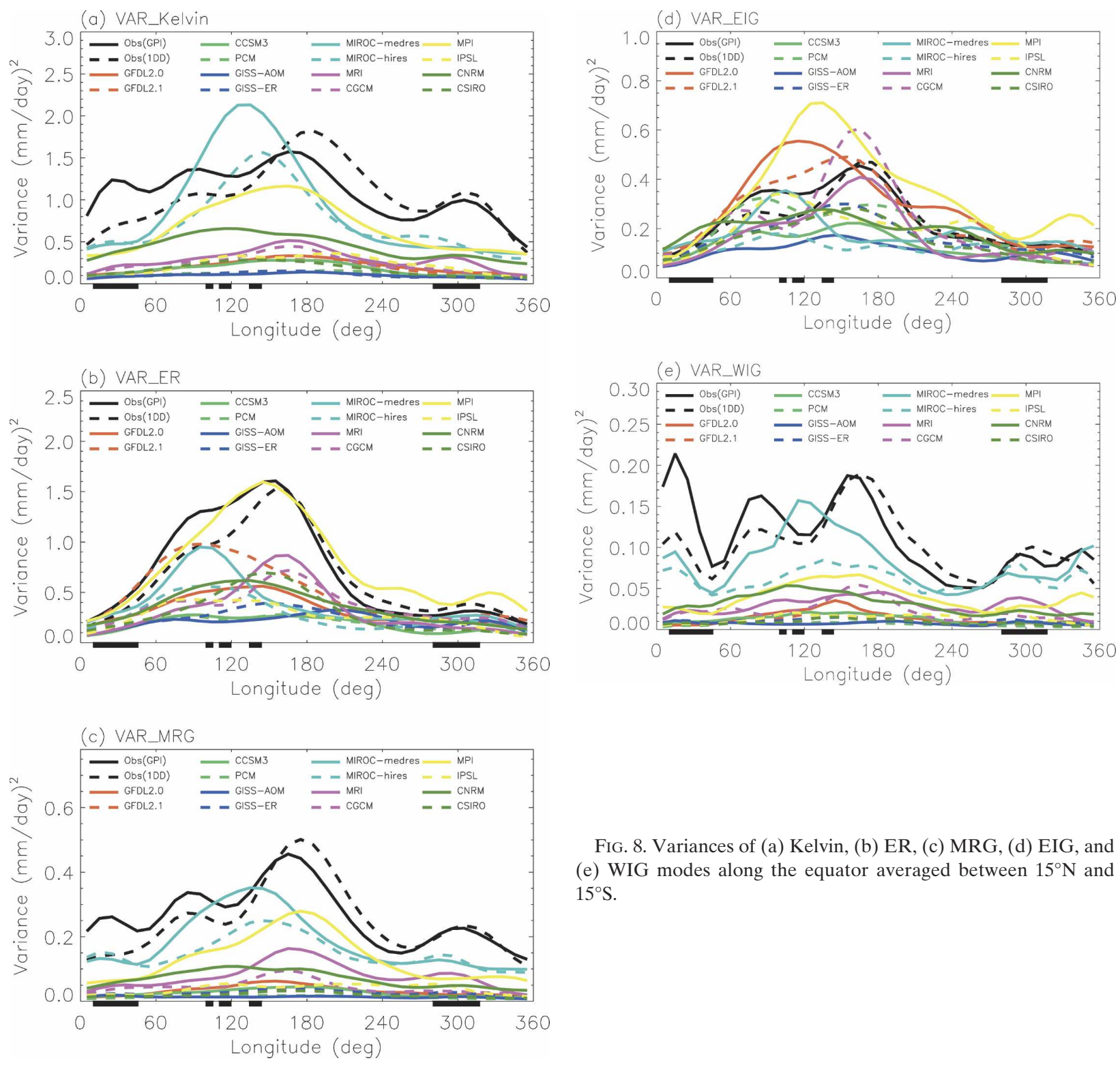

FIG. 8. Variances of (a) Kelvin, (b) ER, (c) MRG, (d) EIG, and (e) WIG modes along the equator averaged between $15^{\circ} \mathrm{N}$ and $15^{\circ} \mathrm{S}$

variance over the Maritime Continent, but they do not capture the observed longitudinal distribution. For the ER mode (Fig. 8b), all models produce too weak variance except ECHAM5/MPI-OM, which faithfully reproduces the observed magnitude and longitudinal distribution of the variance. For the MRG mode (Fig. 8c), which is important for tropical cyclone genesis, all models simulate too weak variance except that MIROC3.2medres simulates strong variance over the Maritime Continent. For the EIG mode (Fig. 8d), unlike other modes, many models (ECHAM5/MPI-OM, GFDLCM2.0, GFDL-CM2.1, CGCM3.1-T47, and MRICGCM2.3.2) produce realistic or too strong variance. In particular, GFDL-CM2.1 reproduces quite well the

observed magnitude and longitudinal distribution. For the WIG mode (Fig. 8e), all models simulate too weak variance except MIROC3.2-medres, which has too much variance over the Maritime Continent.

Overall, there are three important conclusions that can be drawn from Fig. 8. First, most models produce too weak variances for Kelvin, ER, MRG, EIG, and WIG waves, suggesting that the models do not have enough wave-heating feedback in those waves, which is consistent with the too fast phase speeds of those waves in the models. Second, there are one or two models that produce strikingly realistic variances for some of the waves, for example, the ER wave in ECHAM5/MPI$\mathrm{OM}$ and the EIG wave in GFDL-CM2.1. Whether this 
is caused by some fundamental processes in these models or merely by accident needs further study. Third, many models produce very strong EIG variance, which is in sharp contrast with their inability in simulating other modes. This is very interesting and warrants further work.

In summary, about half of the models have signals of convectively coupled equatorial waves, with Kelvin and MRG-EIG waves especially prominent. However, the variance is generally too weak for all wave modes except the EIG wave. Furthermore, the majority of the models with wave signals show phase speeds that are too fast, and scale these disturbances to equivalent depths that are larger than the observed value. Interestingly, this scaling is consistent within a given model across modes, in that both the symmetric and antisymmetric modes scale similarly to a particular equivalent depth, which is indicative of similar physical processes linking the convection and large-scale disturbances within each model.

\section{d. Variance of the MJO mode}

Now we focus on the variance of the MJO mode, that is, the daily variance in the $\mathrm{MJO}$ window of eastward wavenumbers 1-6 and periods of 30-70 days. Figure 9a shows the variance of the MJO anomaly along the equator averaged between $15^{\circ} \mathrm{N}$ and $15^{\circ} \mathrm{S}$. The MJO variance approaches the observed value in 2 of the 14 models, ECHAM5/MPI-OM and CNRM-CM3 (Indian Ocean only), but is less than half of the observed value in the other 12 models. The finding that two models produce nearly realistic MJO precipitation variance is very encouraging since too weak precipitation variance in the MJO wavenumber-frequency band has been a long-standing problem in GCMs, in spite of the fact that many of these models have reasonable values of zonal wind variance. From the viewpoint of weather and climate prediction, a realistic MJO precipitation signal is more desirable because it is the latent heat released by precipitation that drives teleconnections to the subtropics and extratropics and leads to useful predictability.

The $15^{\circ} \mathrm{N}-15^{\circ} \mathrm{S}$ belt analyzed above is a wide belt. As shown by Wang and Rui (1990), eastward-propagating MJO precipitation events occur most often on the equator, with the frequency of occurrence decreasing away from the equator. Therefore, it is of interest to see if the models capture this equatorial maximum of MJO variance. Figure $9 \mathrm{~b}$ is same as Fig. 9a except for precipitation averaged between $5^{\circ} \mathrm{N}$ and $5^{\circ} \mathrm{S}$. For both of the two observational datasets, the variance of the $5^{\circ} \mathrm{N}-$ $5^{\circ} \mathrm{S}$ average is about twice as large as that of the $15^{\circ} \mathrm{N}-$ $15^{\circ} \mathrm{S}$ average. Most of the models, such as ECHAM5/ MPI-OM, CNRM-CM3 (Indian Ocean only), GFDL-
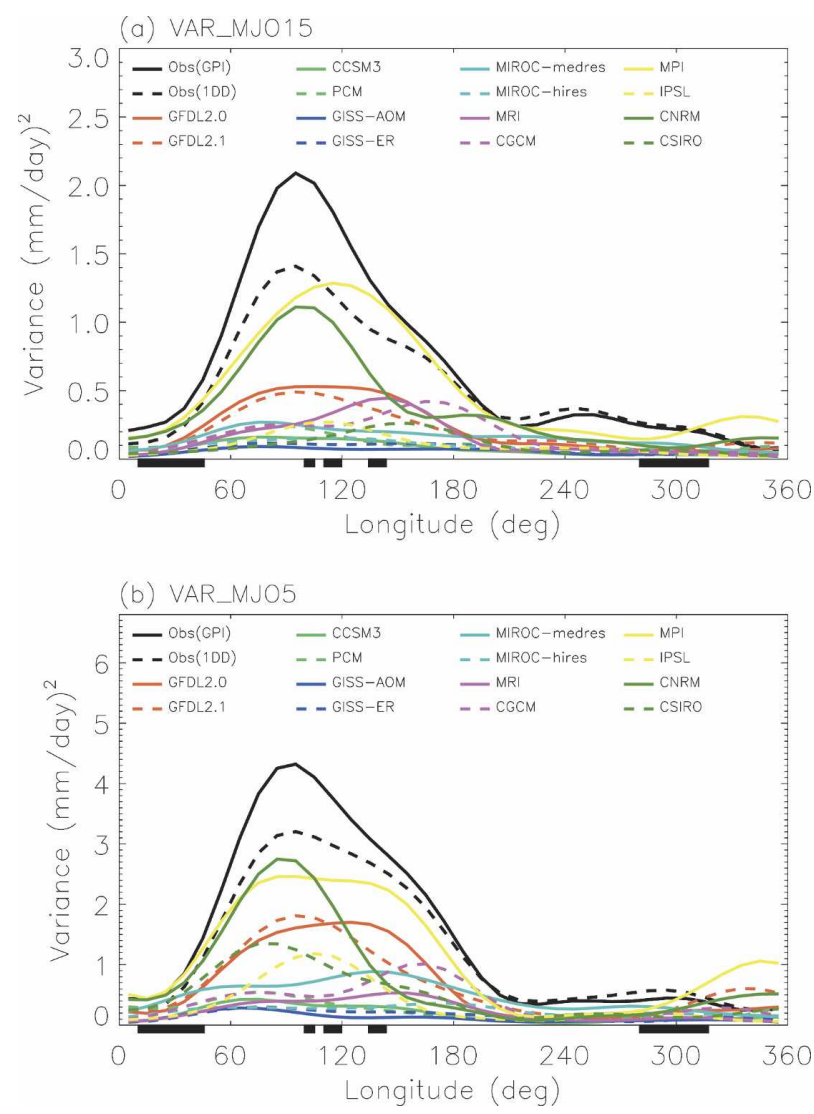

FIG. 9. Variance of the MJO mode along the equator averaged between (a) $15^{\circ} \mathrm{N}-15^{\circ} \mathrm{S}$ and (b) $5^{\circ} \mathrm{N}-5^{\circ} \mathrm{S}$.

CM2.0, GFDL-CM2.1, IPSL-CM4, CSIRO Mk3.0, and CGCM3.1-T47 (western Pacific only), capture this feature quite well, although the models with a doubleITCZ pattern (e.g., CNRM-CM3) cannot reproduce this in the western Pacific. As in Fig. 9a, ECHAM5/ MPI-OM and CNRM-CM3 (Indian Ocean only) are the most realistic with GFDL-CM2.0, GFDL-CM2.1, IPSL-CM4, CSIRO Mk3.0, and CGCM3.1-T47 (western Pacific only) showing improved MJO variance compared to the $15^{\circ} \mathrm{N}-15^{\circ} \mathrm{S}$ data.

In addition to the variance of the eastward MJO, another important index for evaluating the MJO simulation is the ratio between the variance of the eastward MJO and that of its westward counterpart, that is, the westward wavenumber 1-6, 30-70-day mode, which is important for the zonal propagation of tropical intraseasonal oscillation. Figure 10 shows the ratio between the eastward variance and the westward variance averaged over an Indian Ocean box between $5^{\circ} \mathrm{N}-5^{\circ} \mathrm{S}$ and $70^{\circ}-100^{\circ} \mathrm{E}$ (panel a), and a western Pacific box between $5^{\circ} \mathrm{N}-5^{\circ} \mathrm{S}$ and $140^{\circ}-170^{\circ} \mathrm{E}$ (panel b). Over the Indian Ocean (Fig. 10a), the eastward MJO variance roughly triples the westward variance in observations. 

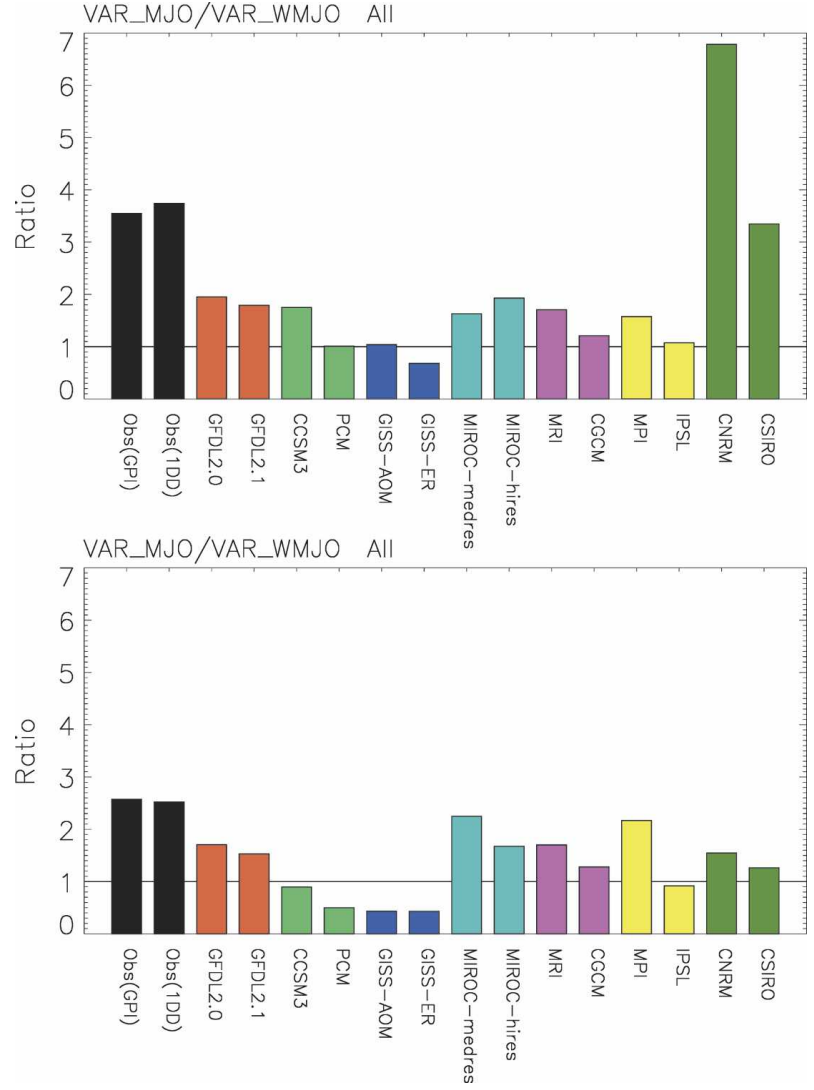

FIG. 10. Ratio between the MJO variance and the variance of its westward counterpart (westward wavenumber 1-6, 30-70-day mode). The variances are averaged over (a) an Indian Ocean box between $5^{\circ} \mathrm{N}-5^{\circ} \mathrm{S}$ and $70^{\circ}-100^{\circ} \mathrm{E}$ and (b) a western Pacific box between $5^{\circ} \mathrm{N}-5^{\circ} \mathrm{S}$ and $140^{\circ}-170^{\circ} \mathrm{E}$.

Of the 14 models, 2 models (CNRM-CM3 and CSIRO Mk3.0) simulate a realistic or too large ratio, while the other 12 models produce a too small ratio, although the ratio is significantly larger than 1 (i.e., eastward variance dominates over westward variance) in 7 of the models (GFDL-CM2.0, GFDL-CM2.1, CCSM3, MIROC3.2-medres, MIROC3.2-hires, MRI-CGCM3.0, and ECHAM5/MPI-OM). Over the western Pacific (Fig. 10b), again, the eastward MJO variance nearly triples its westward counterpart in observations. However, only one model (MIROC3.2-medres) produces a realistic ratio, while all the other models produce a too small ratio.

The competition between the eastward MJO variance and its westward counterpart largely determines the zonal propagation characteristics of the tropical intraseasonal oscillation. A useful method for evaluating the MJO simulation is to look at the propagation of the 30-70-day filtered anomaly of the raw precipitation data, which includes all wavenumbers (zonal mean, eastward wavenumbers 1-6, westward wavenumbers
1-6, eastward wavenumbers 7 and up, westward wavenumbers 7 and up), to see if the MJO mode (the eastward wavenumbers 1-6 mode) dominates over other modes, as is the case in the observations (e.g., Weickmann et al. 1985, 1997; Kiladis and Weickmann 1992; Lin and Mapes 2004). Because the tropical intraseasonal oscillation is dominated by zonally asymmetric, planetary-scale phenomena, the competition is mainly between the MJO and its westward counterpart - the westward wavenumber 1-6 component. Figure 11 shows the lag correlation of the 30-70-day precipitation anomaly averaged between $5^{\circ} \mathrm{N}$ and $5^{\circ} \mathrm{S}$ with respect to itself at $0^{\circ}, 85^{\circ} \mathrm{E}$. Both observational datasets show prominent eastward-propagating signals of the MJO, with a phase speed of about $7 \mathrm{~m} \mathrm{~s}^{-1}$. The models display a wide range of propagation characteristics that are consistent with the ratio between the eastward MJO variance and its westward counterpart shown in Fig. 10a. The two models with a realistic or too large ratio (CNRM-CM3 and CSIRO Mk3.0) show a highly coherent eastward-propagating signal. The phase speed is realistic in CSIRO Mk3.0, but is a little too slow in CNRM-CM3. The models with the eastward/westward ratio being smaller than in observations but still sufficiently larger than one (GFDL-CM2.0, GFDL-CM2.1, CCSM3, MIROC3.2-medres, MIROC3.2-hires, MRICGCM3.0, and ECHAM5/MPI-OM) show only discernable eastward-propagating signals. Other models with the ratio being nearly equal to or smaller than one (PCM, GISS-AOM, GISS-ER, MRI-CGCM2.3.2, and CGCM3.1-T47) show standing oscillations or westward-propagating signals. The results are similar when using a western Pacific reference point (not shown).

Next we apply more detailed scrutiny to the MJO precipitation variance by looking at the shape of the power spectrum. Figure 12a shows the raw spectra of the eastward wavenumber 1-6 component at $0^{\circ}, 85^{\circ} \mathrm{E}$. Because it is difficult to see the shape of spectra for several models with too small variance, we also plotted their normalized spectra (raw spectrum divided by its total variance) in Fig. 12b. Both of the observational datasets show prominent spectral peaks between 30and 70-days periods, with the power of 1DD lower than that of GPI. Most of the models with relatively large MJO variance (ECHAM5/MPI-OM, GFDL-CM2.0, and GFDL-CM2.1) do not show a pronounced spectral peak in the MJO frequency band, but show too red of a spectrum; that is, the variance of the MJO band does not stand above but is simply embedded within a red noise continuum. Most models with weak MJO variance (e.g., CCSM3, PCM) also lack a spectral peak in the MJO band, and show a too red spectrum. The only model showing a prominent spectral peak in the MJO 

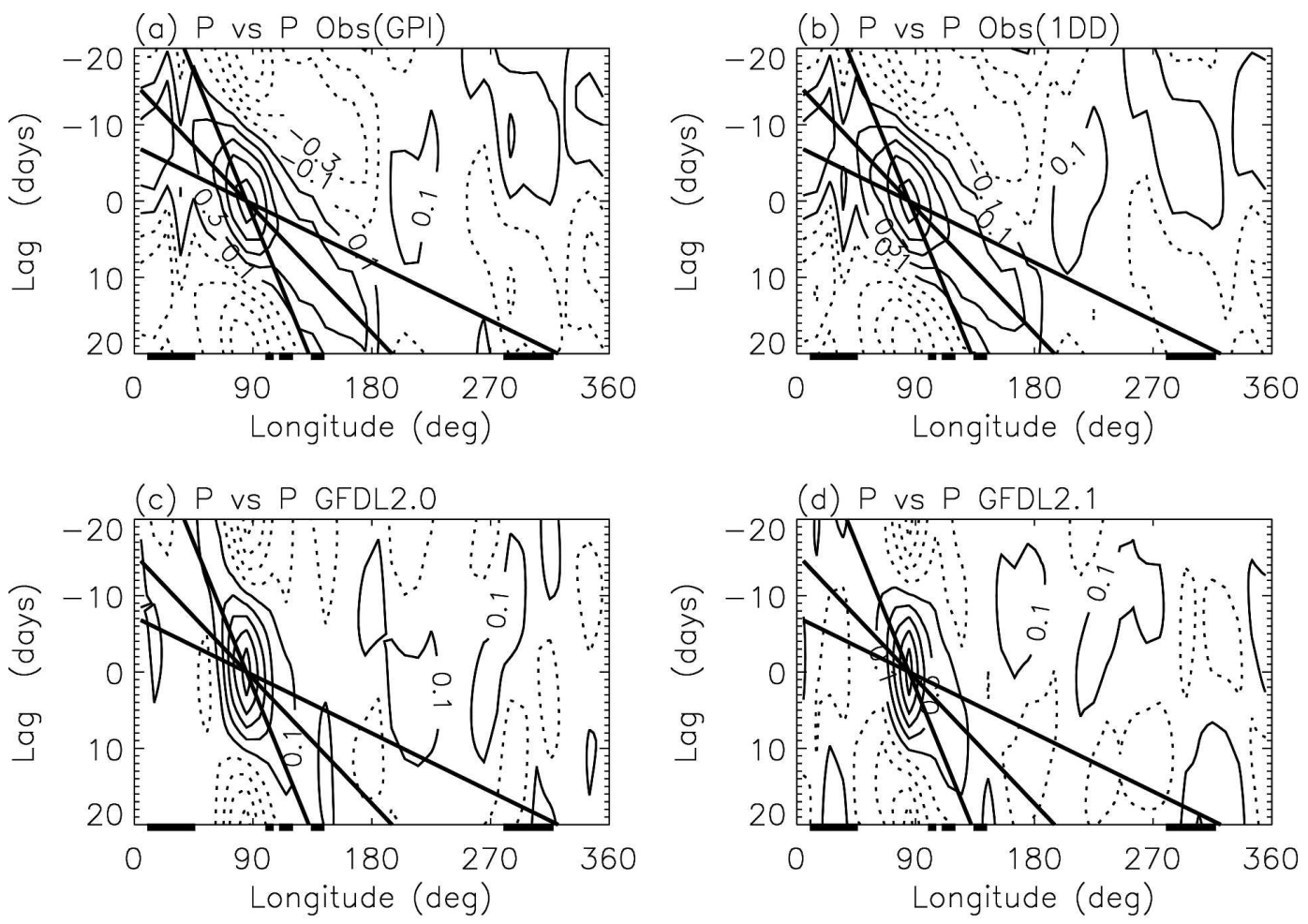

(d) $P$ vs $P$ GFDL2.1
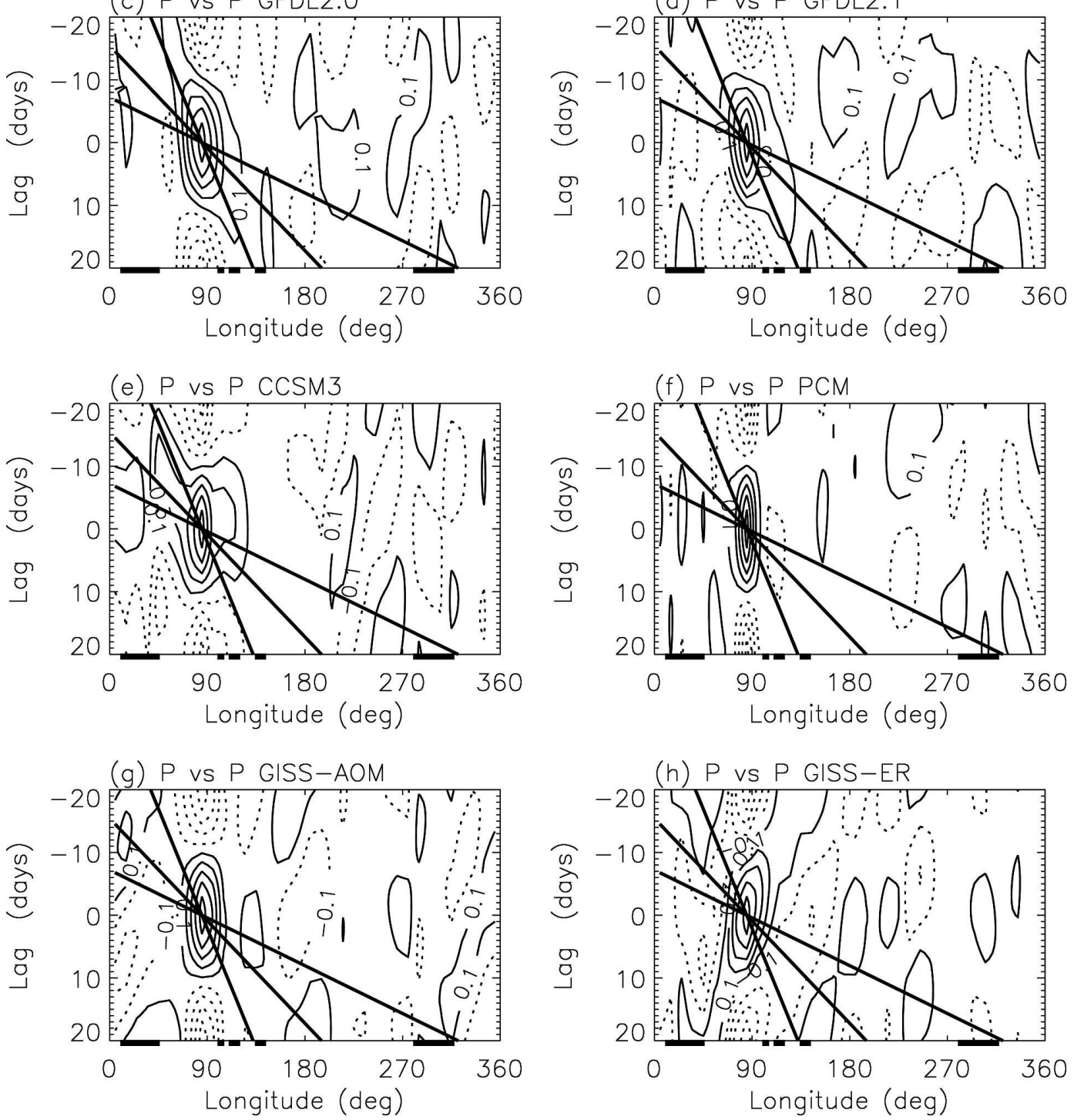

FIG. 11. Lag correlation of the 30-70-day precipitation anomaly averaged along the equator between $5^{\circ} \mathrm{N}$ and $5^{\circ} \mathrm{S}$ with respect to itself at $0^{\circ}, 85^{\circ} \mathrm{E}$. The three thick lines correspond to phase speed of 3,7 , and $15 \mathrm{~m} \mathrm{~s}^{-1}$, respectively. 

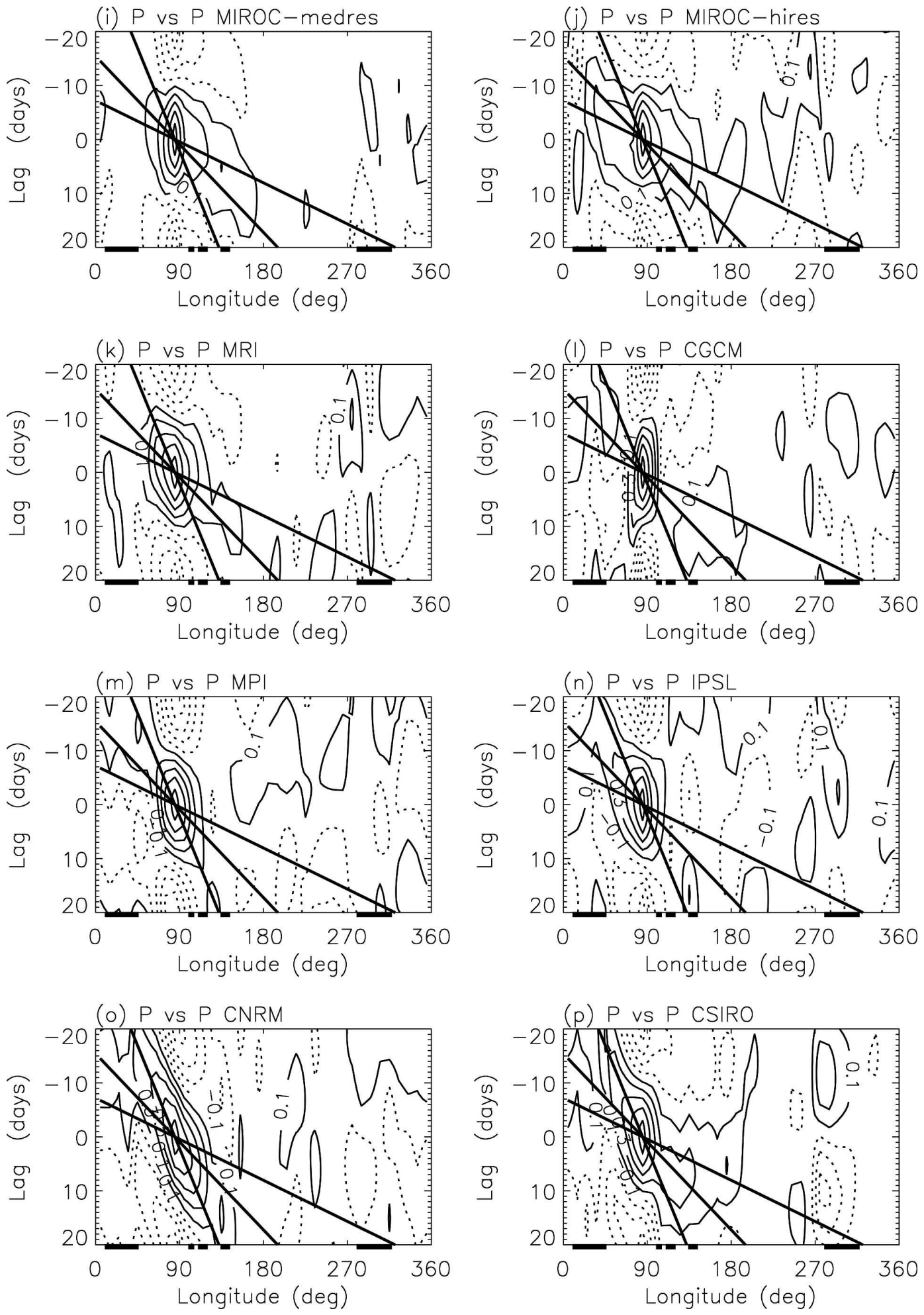

FIG. 11. (Continued) 

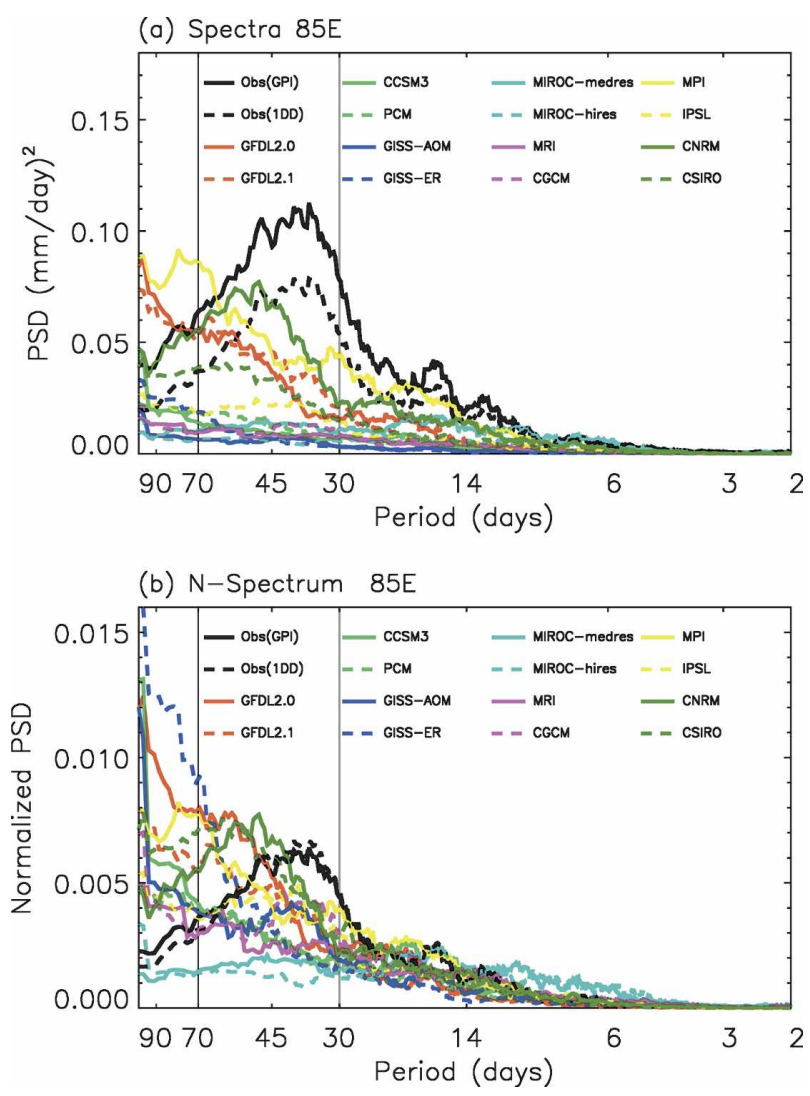

FIG. 12. Spectrum of the eastward wavenumber 1-6 component of equatorial precipitation $\left(5^{\circ} \mathrm{N}-5^{\circ} \mathrm{S}\right)$ at $0^{\circ}, 85^{\circ} \mathrm{E}$ for two observational datasets and 14 models: (a) raw and (b) normalized spectrum. Frequency spectral width $1 / 100 \mathrm{cpd}$.

band is CNRM-CM3, whose power is similar to that of 1DD. Results for $0^{\circ}, 155^{\circ} \mathrm{E}$ (western Pacific) are similar (not shown).

For the AMIP models, Slingo et al. (1996) found that deep convection schemes with CAPE-type closure tend to produce more realistic MJO signals than schemes with moisture-convergence-type closure, but we find a reverse dependence in the IPCC AR4 models. The two models that arguably do best at simulating the MJO, CNRM-CM3 and ECHAM5/MPI-OM, are the only ones having convective closures/triggers linked in some way to moisture convergence. One possible reason is that the moisture-convergence-type closures/triggers tie the convection more closely with large-scale wave circulation and thus enhance the wave-heating feedback in the MJO.

There does not appear to be a systematic dependence of MJO variance on a model's horizontal resolution. For example, the high-resolution version of the MIROC model produces weaker MJO variance than the medium-resolution version, similar to the result of Slingo et al. (1996). Alternatively, IPSL-CM4, which has relatively low resolution among all of the models, does produce above-average MJO variance. Therefore, it seems that a model's horizontal resolution is less important for simulating the MJO than other factors such as model physics or air-sea coupling, which is consistent with the results of Duffy et al. (2003).

To summarize, the MJO variance approaches the observed value in 2 of the 14 models, but is less than half of the observed value in the other 12 models. The ratio between the eastward MJO variance and the variance of its westward counterpart is too small in most of the models, which is consistent with the lack of highly coherent eastward propagation of the MJO in many models. Moreover, the MJO variance in 13 of the 14 models does not come from a pronounced spectral peak, but usually comes from part of an overreddened spectrum. We did not find a systematic dependence of MJO variance on a model's horizontal resolution. The two models that arguably do best at simulating the MJO (CNRM-CM3 and ECHAM5/MPI-OM) are the only ones having convective closures/triggers linked in some way to moisture convergence.

\section{e. Autocorrelation of precipitation}

The redness of many model spectra shown in Fig. 12 brings to mind a "red noise" spectrum of a first-order linear Markov process (Gilman 1963; Jenkins and Watts 1968). Following Gilman (1963), the first-order Markov process may be expressed as

$$
X_{n}=\rho X_{n-1}+y_{n},
$$

where $\left[y_{n}\right]$, the expected value of $y_{n}$, is zero and $\left[y_{n}{ }^{2}\right]$ $=\sigma^{2}$. As derived by Gilman (1963), the autocorrelation function is

$$
\left[X_{n} X_{n-k}\right] /\left[X_{n}^{2}\right]=\rho^{k}
$$

and the raw estimate of spectral density is

$$
\operatorname{PSD}=(1-\rho) /\left\{1-2 \rho \cos (h \pi / M)+\rho^{2}\right\}
$$

in which $M$ is maximum lag and $h$ is frequency. As shown by Eq. (2), $\rho$ is the lag-one autocorrelation and is hereafter referred to as the persistence of the time series. Figure 13a shows the family of red noise spectra associated with different values of $\rho$. When $\rho$ increases from small to large values, the spectrum changes from nearly white noise to red noise. The corresponding autocorrelation functions [Eq. (2)] are shown in Fig. 13b. Because the autocorrelation function is a simple power function of $\rho$, it becomes a straight line when plotted against a logarithmic ordinate.

For the first-order Markov process, the redness of the spectrum is determined by its lag-one autocorrela- 


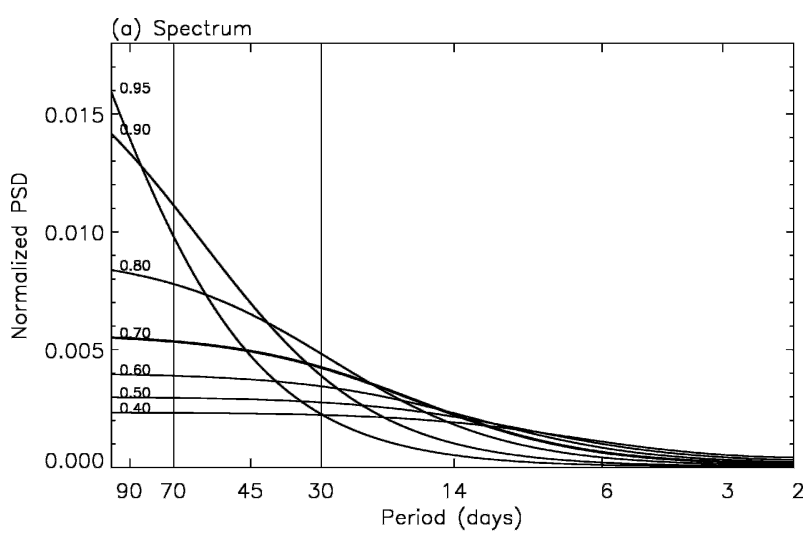

(b) Auto-correlation

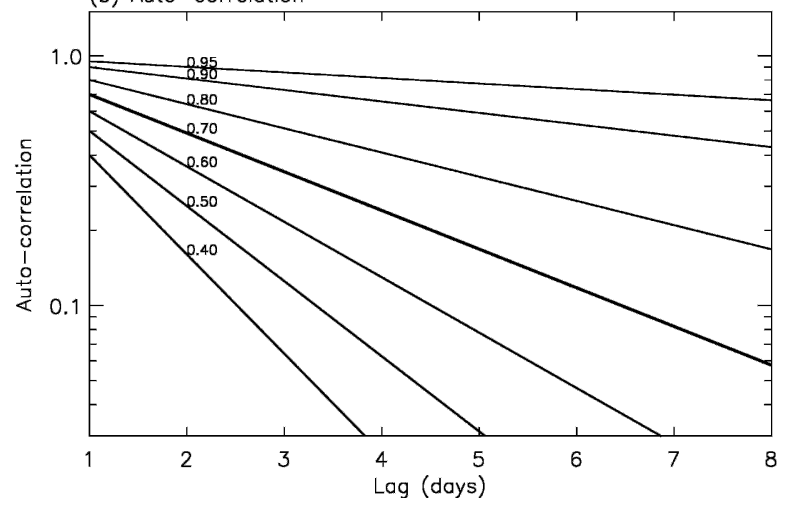

FIG. 13. (a) Spectrum and (b) autocorrelation of theoretical Markov process.

tion. Therefore, we plot in Fig. 14 the autocorrelation function of precipitation at $0^{\circ}, 85^{\circ} \mathrm{E}$. Both observational datasets have a $\rho$ of about 0.7 . Most models have too large values of $\rho$, which is consistent with their spectra being too red (Fig. 12). Several models (CNRM-CM3, MRI-CGCM2.3.2, MIROC3.2-medres, and MIROC3.2hires) have a $\rho$ similar to or smaller than the observed value. Results for $0^{\circ}, 155^{\circ} \mathrm{E}$ (western Pacific) are similar (not shown).

The physical meaning of $\rho$ is the persistence of precipitation in the region of interest. Therefore, Fig. 14 indicates that most of the models have too strong persistence of precipitation, which is closely associated with their overreddened spectra. In addition to the shape of the spectrum, the precipitation persistence also affects the modes at the high-frequency end of the spectrum, such as the WIG mode (the 2-day wave) and the MRG-EIG modes (the 3-6-day synoptic disturbances). A too strong persistence tends to suppress the high-frequency modes (see Fig. 13a) and may contribute to the generally too weak variances of these modes in the IPCC models. We will discuss the factors affecting the persistence of precipitation in the next section.

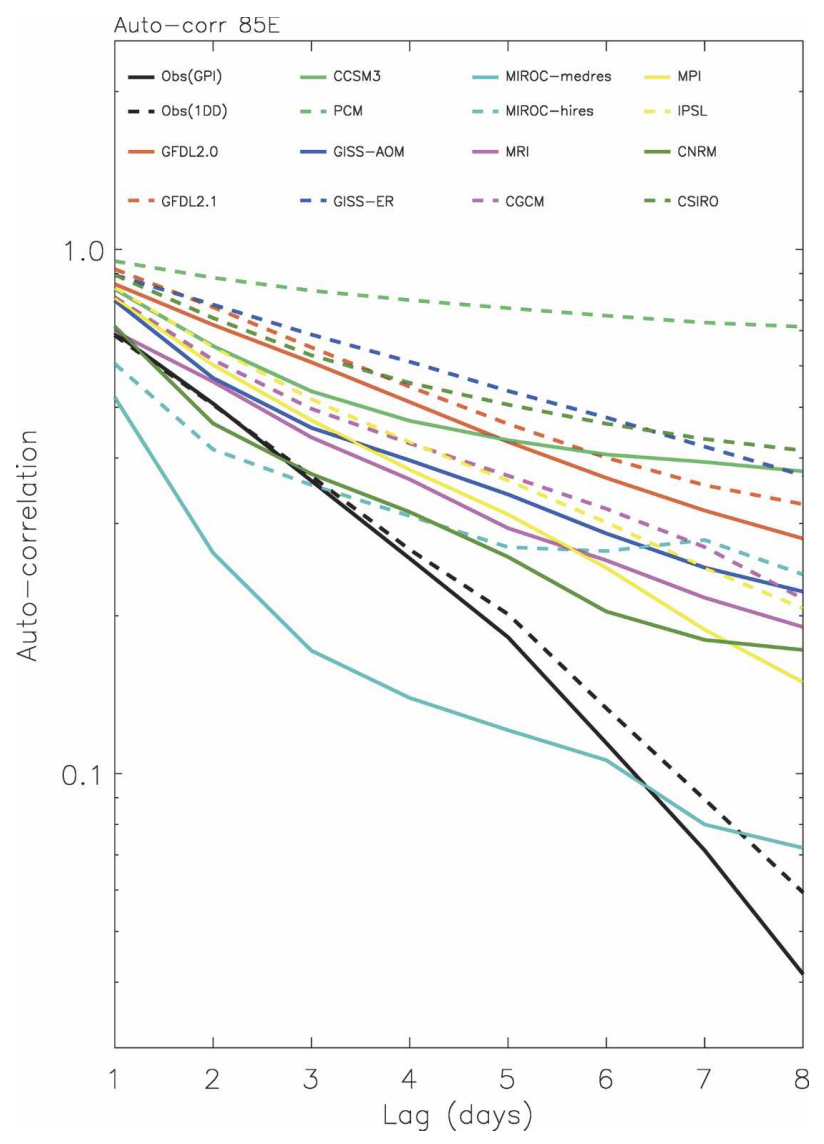

FIG. 14. Autocorrelation of precipitation at $0^{\circ}, 85^{\circ} \mathrm{E}$.

\section{Summary and discussion}

This study evaluates the tropical intraseasonal variability, and especially the fidelity of MJO simulations, in 14 IPCC AR4 coupled GCMs. Eight years of daily precipitation data from each model's twentieth-century climate simulation are analyzed and compared with daily satellite-retrieved precipitation. Space-time spectral analysis is used to obtain the variance and phase speed of dominant convectively coupled equatorial waves, including the MJO, Kelvin, ER, MRG, EIG, and WIG waves. The variance and propagation of the MJO, defined as the eastward wavenumber 1-6, 30-70-day mode, are examined in detail.

The results show that current state-of-the-art GCMs still have significant problems and display a wide range of skill in simulating the tropical intraseasonal variability. The total intraseasonal (2-128 day) variance of precipitation is too weak in most of the models. About half of the models have signals of convectively coupled equatorial waves, with Kelvin and MRG-EIG waves especially prominent. However, the variances are generally too weak for all wave modes except the EIG 
wave, and the phase speeds are generally too fast, being scaled to excessively deep equivalent depths. An interesting result is that this scaling is consistent within a given model across modes, in that both the symmetric and antisymmetric modes scale similarly to a particular equivalent depth. Excessively deep equivalent depths suggest that these models may not have a large enough reduction in their "effective static stability" by diabatic heating.

The MJO variance approaches the observed value in 2 of the 14 models, but is less than half of the observed value in the other 12 models. The ratio between the eastward MJO variance and the variance of its westward counterpart is too small in most of the models, which is consistent with the lack of highly coherent eastward propagation of the MJO in many models. Moreover, the MJO variance in 13 of the 14 models does not come from a pronounced spectral peak, but usually comes from part of an overreddened spectrum, which in turn is associated with a too strong persistence of equatorial precipitation. The two models that arguably do best at simulating the MJO are the only ones having convective closures/triggers linked in some way to moisture convergence.

Our results reveal two common biases in many climate models, namely, too large equivalent depths for equatorial waves and too strong persistence of equatorial precipitation. Equivalent depths that are too deep for equatorial modes in many models suggest that they may have a too large "effective static stability." The effective static stability is due to the partial cancellation between diabatic heating and adiabatic cooling associated with vertical motion (Gill 1982; Neelin and Held 1987; Emanuel et al. 1994), which would lead to a reduction of the implied equivalent depth of a convecting disturbance (WK; Haertel and Kiladis 2004). The effective static stability is thus affected by the vertical structure of moist static energy, the vertical profile of upward motion associated with diabatic heating profile, the surface latent and sensible heat flux, and the column-integrated radiative heating (e.g., Neelin and Held 1987; Yu et al. 1998). Therefore, in future studies, it would be interesting to directly evaluate the effective static stability in the models, and if it is indeed too large, examine which of the above factors are at the cause.

The persistence of equatorial precipitation is strongly affected by subgrid-scale processes, and may be improved by refining a model's moist physics. Since our results indicate that precipitation persistence is closely tied to the redness of the background spectrum, if we can make the persistence more realistic through improving model physics, we may be able to get a more realistic background spectrum. The observed weak persistence of precipitation may be associated with the well-known self-suppression processes in deep convection, which can be summarized as follows. Deep convective updrafts are usually associated with saturated and unsaturated convective downdrafts penetrating into the boundary layer and mesoscale downdrafts penetrating to the lower troposphere above the boundary layer (e.g., Zipser 1969, 1977; Houze 1977, 1982; Mapes and Houze 1995; Mapes and Lin 2005). Convective downdrafts, especially the unsaturated convective downdrafts, significantly dry and cool the boundary layer (e.g., Zipser 1969; Houze 1977; Barnes and Garstang 1982) and, therefore, decrease the initial entropy of future convective updrafts. Mesoscale downdrafts dry the lower troposphere above the boundary layer, leading to the famous "onion" sounding (e.g., Zipser 1977), and a too dry lower troposphere may decrease the buoyancy of the future convective updrafts through entrainment (e.g., Brown and Zhang 1997). Therefore, in the wake of a deep convection event, both of the above processes suppress the development of new deep convection and, thus, decrease the persistence of precipitation.

The current GCMs have not included all of the above self-suppression processes in deep convection (Table 1). Although many of the models have saturated convective downdrafts, only a few of them have unsaturated convective downdrafts (e.g., Emanuel 1991), and none of the models have mesoscale downdrafts. Moreover, the sensitivity of deep convection to moisture in the lower troposphere above the boundary layer has not been well represented in many models, especially because they include undiluted or weakly diluted members in the ensemble of convective updrafts. However, this sensitivity is enhanced in some models, for example, by including only the significantly diluted convective updrafts (e.g., Tokioka et al. 1988; Tiedtke 1989; Bougeault 1985), or by adding explicit trigger functions (e.g., Emori et al. 2001). Our results suggest that it is important to incorporate these self-suppression processes in deep convection in order to get realistic persistence of precipitation.

When models improve the representation of selfsuppression processes in deep convection, the persistence of precipitation may decrease and approach the observed value. As suggested by the spectrum of the theoretical Markov process (Fig. 13a), decreasing persistence may have different effects on the MJO variance in different models. For models now having a very strong persistence (e.g., $\rho>0.9$ ), decreasing persistence may decrease the variance for periods longer than 70 days but increase the variance in the 30-70-day MJO 
band. However, for models now having medium persistence (e.g., $0.75<\rho<0.9$ ), decreasing persistence may decrease the variances for both periods longer than 70 days and periods of 30-70 days, although it is also possible that spectral peaks previously embedded within the red noise spectra will be unveiled. Nevertheless, the point is that most of the models have a positive bias in their persistence of precipitation, which may need to be alleviated.

It is important to note that even a realistic persistence can by itself only create a red noise spectrum, but not a spectral peak. To generate a spectral peak, convectively coupled large-scale waves and wave-heating feedback must be involved. This leads us to the following questions:

1) Are the MJO precipitation anomalies in the models associated with realistic MJO wave structure?

2) Are the wave-heating feedbacks well simulated in the models?

3) What causes the spectral peak in the CNRM-CM3 model?

Fortunately, 10 of the 14 models have 3D upper-air data available, which makes it possible to analyze both the wave structure and wave-heating feedback. We are currently analyzing these structures and will report the results in separate studies.

Acknowledgments. This study benefited much from discussions with Dave Randall, Sumant Nigam, Shuntai Zhou, Isaac Held, Steve Klein, Eric Maloney, Norm McFarlane, Gavin Schmidt, and Yogesh Sud. The careful and insightful reviews by Duane Waliser and an anonymous reviewer helped significantly to improving the manuscript. Gary Russell kindly provided a detailed description of the GISS-AOM model. We acknowledge the international modeling groups for providing their data for analysis, the Program for Climate Model Diagnosis and Intercomparison (PCMDI) for collecting and archiving the model data, the JSC/ CLIVAR Working Group on Coupled Modeling (WGCM) and their Coupled Model Intercomparison Project (CMIP) and Climate Simulation Panel for organizing the model data analysis activity, and the IPCC WG1 TSU for technical support. The IPCC Data Archive at Lawrence Livermore National Laboratory is supported by the Office of Science, U.S. Department of Energy. J. L. Lin was supported by the U.S. Climate Variability and Predictability Program (CLIVAR) Climate Model Evaluation Project (CMEP; information available online at http://www.usclivar.org/); the NOAA OGP CLIVAR-Pacific Program; NOAA OGP CDEP Program; the NASA Modeling, Analysis and
Prediction (MAP) Program; and the NOAA Geophysical Fluid Dynamics Laboratory. B. E. Mapes was supported by NSF ATM-0336790K and the NOAA OGP CLIVAR-Pacific Program. K. R. Sperber was supported under the auspices of the U.S. Department of Energy Office of Science, Climate Change Prediction Program by the University of California Lawrence Livermore National Laboratory under Contract W-7405Eng-48. A. Del Genio was supported by the NASA Precipitation Measurement Missions Program.

\section{REFERENCES}

Barnes, G. M., and M. Garstang, 1982: Subcloud layer energetics of precipitating convection. Mon. Wea. Rev., 110, 102-117.

Berbery, E. H., and J. Nogues-Paegle, 1993: Intraseasonal interactions between the Tropics and extratropics in the Southern Hemisphere. J. Atmos. Sci., 50, 1950-1965.

Bergman, J. W., H. H. Hendon, and K. M. Weickmann, 2001: Intraseasonal air-sea interactions at the onset of El Niño. $J$. Climate, 14, 1702-1719.

Bessafi, M., and M. C. Wheeler, 2006: Modulation of south Indian Ocean tropical cyclones by the Madden-Julian oscillation and convectively coupled equatorial waves. Mon. Wea. Rev., 134, 638-656.

Bougeault, P., 1985: A simple parameterization of the large-scale effects of cumulus convection. Mon. Wea. Rev., 113, 21082121.

Brown, R. G., and C. Zhang, 1997: Variability of midtropospheric humidity and its effect on cloud-top height distribution during TOGA COARE. J. Atmos. Sci., 54, 2760-2774.

Carvalho, L. M. V., C. Jones, and T. Ambrizzi, 2005: Opposite phases of the Antarctic Oscillation and relationships with intraseasonal to interannual activity in the Tropics during the austral summer. J. Climate, 18, 702-718.

Del Genio, A. D., and M.-S. Yao, 1993: Efficient cumulus parameterization for long-term climate studies: The GISS scheme. The Representation of Cumulus Convection in Numerical Models, Meteor. Monogr., No. 46, Amer. Meteor. Soc., 181184.

Dickinson, M., and J. Molinari, 2002: Mixed Rossby-gravity waves and western Pacific tropical cyclogenesis. Part I: Synoptic evolution. J. Atmos. Sci., 59, 2183-2196.

Duchan, C. E., 1979: Lanczos filtering in one and two dimensions. J. Appl. Meteor., 18, 1016-1022.

Duffy, P. B., B. Govindasamy, J. P. Iorio, J. Milovich, K. R. Sperber, K. E. Taylor, M. F. Wehner, and S. L. Thompson, 2003: High-resolution simulation of global climate. Part I: Present climate. Climate Dyn., 21, 371-390.

Emanuel, K. A., 1987: An air-sea interaction model of intraseasonal oscillation in the tropics. J. Atmos. Sci., 44, 2324-2340.

_ 1991: A scheme for representing cumulus convection in large-scale models. J. Atmos. Sci., 48, 2313-2329.

_ J. D. Neelin, and C. S. Bretherton, 1994: On large-scale circulations in convecting atmospheres. Quart. J. Roy. Meteor. Soc., 120, 1111-1143.

Emori, S., T. Nozawa, A. Numaguti, and I. Uno, 2001: Importance of cumulus parameterization for precipitation simulation over East Asia in June. J. Meteor. Soc. Japan, 79, 939-947.

Flatau, M., P. J. Flatau, P. Phoebus, and P. P. Niiler, 1997: The feedback between equatorial convection and local radiative 
and evaporative processes: The implications for intraseasonal oscillations. J. Atmos. Sci., 54, 2373-2386.

Gill, A. E., 1982: Studies of moisture effects in simple atmospheric models: The stable case. Geophys. Astrophys. Fluid Dyn., 19, $119-152$.

Gilman, D. L., F. J. Fuglister, and J. M. Mitchell Jr., 1963: On the power spectrum of "red noise. J. Atmos. Sci., 20, 182-184.

Goswami, B. N., R. S. Ajayamohan, P. K. Xavier, and D. Sengupta, 2003: Clustering of synoptic activity by Indian summer monsoon intraseasonal oscillations. Geophys. Res. Lett., 30, 1431-1434.

Gregory, D., and P. R. Rowntree, 1990: A mass flux convection scheme with representation of cloud ensemble characteristics and stability-dependent closure. Mon. Wea. Rev., 118, 14831506.

Haertel, P. T., and G. N. Kiladis, 2004: Dynamics of 2-day equatorial waves. J. Atmos. Sci., 61, 2707-2721.

Hartten, L. M., 1996: Synoptic settings of westerly wind bursts. $J$. Geophys. Res., 101 (D12), 16 997-17 019.

Hayashi, Y., and D. G. Golder, 1986: Tropical intraseasonal oscillations appearing in a GFDL general circulation model and FGGE data. Part I: Phase propagation. J. Atmos. Sci., 43, 3058-3067.

-, and A. Sumi, 1986: The 30-40 day oscillation simulated in an "aquaplanet" model. J. Meteor. Soc. Japan, 64, 451-466.

— appearing in a GFDL general circulation model and FGGE data. Part II: Structure. J. Atmos. Sci., 45, 3017-3033.

Hendon, H. H., 2000: Impact of air-sea coupling on the MaddenJulian oscillation in a general circulation model. J. Atmos. Sci., 57, 3939-3952.

_ C. Zhang, and J. D. Glick, 1999: Interannual variation of the MJO during austral summer. J. Climate, 12, 2538-2550.

Higgins, R. W., J.-K. E. Schemm, W. Shi, and A. Leetmaa, 2000: Extreme precipitation events in the western United States related to tropical forcing. J. Climate, 13, 793-820.

Houze, R. A., 1977: Structure and dynamics of a tropical squallline system. Mon. Wea. Rev., 105, 1540-1567.

— 1982: Cloud clusters and large-scale vertical motions in the Tropics. J. Meteor. Soc. Japan, 60, 396-410.

Huffman, G. J., R. F. Adler, M. M. Morrissey, S. Curtis, R. Joyce, B. McGavock, and J. Susskind, 2001: Global precipitation at $1^{\circ}$ daily resolution from multisatellite observations. $J$. $\mathrm{Hy}$ drometeor., 2, 36-50.

Inness, P. M., and J. M. Slingo, 2003: Simulation of the MaddenJulian oscillation in a coupled general circulation model. Part I: Comparisons with observations and an atmosphere-only GCM. J. Climate, 16, 345-364.

- - S. J. Woolnough, R. B. Neale, and V. D. Pope, 2001: Organization of tropical convection in a GCM with varying vertical resolution: Implications for the simulation of the Madden-Julian oscillation. Climate Dyn., 17, 777-793.

Janowiak, J. E., and P. A. Arkin, 1991: Rainfall variations in the Tropics during 1986-1989, as estimated from observations of cloud-top temperatures. J. Geophys. Res., 96 (Suppl.), 33593373 .

Jenkins, G. M., and D. G. Watts, 1968: Spectral Analysis and Its Applications. Holden Day, 525 pp.

Jones, C., and J.-K. E. Schemm, 2000: The influence of intraseasonal variations on medium-range weather forecasts over South America. Mon. Wea. Rev., 128, 486-494.

Kemball-Cook, S., and B. Wang, 2001: Equatorial waves and air- sea interaction in the boreal summer intraseasonal oscillation. J. Climate, 14, 2923-2942.

Kessler, W. S., M. J. McPhaden, and K. M. Weickmann, 1995: Forcing of intraseasonal Kelvin waves in the equatorial Pacific. J. Geophys. Res., 100, 10 613-10 631.

Kiladis, G. N., and K. M. Weickmann, 1992: Circulation anomalies associated with tropical convection during northern winter. Mon. Wea. Rev., 120, 1900-1923.

_ , G. A. Meehl, and K. M. Weickmann, 1994: Large-scale circulation associated with westerly wind bursts and deep convection over the western equatorial Pacific. J. Geophys. Res, 99, 18 527-18 544

, K. H. Straub, and P. T. Haertel, 2005: Zonal and vertical structure of the Madden-Julian oscillation. J. Atmos. Sci., 62, 2790-2809.

Knutson, T. R., and K. M. Weickmann, 1987: 30-60 day atmospheric oscillations: Composite life cycles of convection and circulation anomalies. Mon. Wea. Rev., 115, 1407-1436.

$\longrightarrow$, - and J. E. Kutzbach, 1986: Global-scale intraseasonal oscillations of outgoing longwave radiation and $250 \mathrm{mb}$ zonal wind during Northern Hemisphere summer. Mon. Wea. Rev., 114, 605-623.

Kuma, K. I., 1994: The Madden and Julian and tropical disturbances in an aqua-planet version of JMA global model with T63 and T159 resolution. J. Meteor. Soc. Japan, 72, 147-172.

Lau, N. C., I. M. Held, and J. D. Neelin, 1988: The Madden-Julian oscillations in an idealized general circulation model. $J$. Atmos. Sci., 45, 3810-3831.

Lawrence, D. M., and P. J. Webster, 2002: The boreal summer intraseasonal oscillation: Relationship between northward and eastward movement of convection. J. Atmos. Sci., 59, 1593-1606.

Lee, M.-I., I.-S. Kang, J.-K. Kim, and B. E. Mapes, 2001: Influence of cloud-radiation interaction on simulating tropical intraseasonal oscillation with an atmospheric general circulation model. J. Geophys. Res., 106, 14 219-14 233.

,-- , and - 2003: Impacts of cumulus convection parameterization on aqua-planet AGCM simulations of tropical intraseasonal variability. J. Meteor. Soc. Japan, 81, 963-992.

Liebmann, B., H. H. Hendon, and J. D. Glick, 1994: The relationship between tropical cyclones of the western Pacific and Indian Oceans and the Madden-Julian oscillation. J. Meteor. Soc. Japan, 72, 401-411.

Lin, J. L., and B. E. Mapes, 2004: Radiation budget of the tropical intraseasonal oscillation. J. Atmos. Sci., 61, 2050-2062.

, - — M. H. Zhang, and M. Newman, 2004: Stratiform precipitation, vertical heating profiles, and the Madden-Julian oscillation. J. Atmos. Sci., 61, 296-309.

,-- , and — 2005: Zonal momentum budget of the Madden-Julian oscillation: The source and strength of equivalent linear damping. J. Atmos. Sci., 62, 2172-2188.

Madden, R. A., and P. R. Julian, 1971: Detection of a 40-50 day oscillation in the zonal wind in the tropical Pacific. J. Atmos. Sci., 28, 702-708.

— , and - 1972: Description of global-scale circulation cells in the tropics with a 40-50 day period. J. Atmos. Sci., 29, $1109-1123$.

Majda, A. J., and J. A. Biello, 2004: A multi-scale model for tropical intraseasonal oscillations. Proc. Natl. Acad. Sci., 101, $4736-4741$.

- and - 2005: A new multiscale model for the MaddenJulian oscillation. J. Atmos. Sci., 62, 1694-1721.

Maloney, E. D., and D. L. Hartmann, 2000: Modulation of eastern 
North Pacific hurricanes by the Madden-Julian oscillation. $J$. Climate, 13, 1451-1460.

—_, and _ 2001a: The Madden-Julian oscillation, barotropic dynamics, and North Pacific tropical cyclone formation. Part I: Observations. J. Atmos. Sci., 58, 2545-2558.

— in the NCAR CCM3 to changes in convective parameterization. J. Climate, 14, 2015-2034.

Mapes, B. E., and R. A. Houze, 1995: Diabatic divergence profiles in western Pacific mesoscale convective systems. J. Atmos. Sci., 52, 1807-1828.

— , and J. L. Lin, 2005: Doppler radar observations of mesoscale wind divergence in regions of tropical convection. Mon. Wea. Rev., 133, 1808-1824.

Matsuno, T., 1966: Quasi-geostrophic motions in the equatorial area. J. Meteor. Soc. Japan, 44, 25-43.

Miller, A. J., S. Zhou, and S.-K. Yang, 2003: Relationship of the Arctic and Antarctic Oscillation to outgoing longwave radiation. J. Climate, 16, 1583-1592.

Mo, K. C., and R. W. Higgins, 1998: Tropical influences on California precipitation. J. Climate, 11, 412-430.

Moncrieff, M. W., 2004: Analytic representation of the large-scale organization of tropical convection. J. Atmos. Sci., 61, 15211538.

Moorthi, S., and M. J. Suarez, 1992: Relaxed Arakawa-Schubert: A parameterization of moist convection for general circulation models. Mon. Wea. Rev., 120, 978-1002.

Neelin, J. D., and I. M. Held, 1987: Modeling tropical convergence based on the moist static energy budget. Mon. Wea. Rev., 115, $3-12$.

Nordeng, T. E., 1994: Extended versions of the convective parameterization scheme at ECMWF and their impact on the mean and transient activity of the model in the tropics. ECMWF Tech. Memo. 206, European Centre for Medium-Range Weather Forecasts, Reading, United Kingdom, 41 pp.

Paegle, J. N., L. A. Byerle, and K. C. Mo, 2000: Intraseasonal modulation of South American summer precipitation. Mon. Wea. Rev., 128, 837-850.

Pan, D.-M., and D. A. Randall, 1998: A cumulus parameterization with a prognostic closure. Quart. J. Roy. Meteor. Soc., 124, 949-981.

Park, C. K., D. M. Straus, and K.-M. Lau, 1990: An evaluation of the structure of tropical intraseasonal oscillations in three general circulation models. J. Meteor. Soc. Japan, 68, 403417.

Russell, G. L., J. R. Miller, and D. Rind, 1995: A coupled atmosphere-ocean model for transient climate change studies. Atmos.-Ocean, 33, 683-730.

Salby, M., and R. R. Garcia, 1987: Transient response to localized episodic heating in the Tropics. Part I: Excitation and shorttime near-field behavior. J. Atmos. Sci., 44, 458-498.

— , and H. H. Hendon, 1994: Intraseasonal behavior of clouds, temperature, and motion in the Tropics. J. Atmos. Sci., 51, 2207-2224.

Schubert, S., R. Dole, H. Van den Dool, M. Suarez, and D. Waliser, 2002: Proceedings from a workshop on "Prospects for improved forecasts of weather and short-term climate variability on subseasonal (2 week to 2 month) time scales." NASA/TM 2002-104606, Vol. 23, 171 pp.

Simpson, J., R. F. Adler, and G. R. North, 1988: A proposed Tropical Rainfall Measuring Mission (TRMM) satellite. Bull. Amer. Meteor. Soc., 69, 278-295.
Slingo, J. M., and Coauthors, 1996: Intraseasonal oscillations in 15 atmospheric general circulation models: Results from an AMIP diagnostic subproject. Climate Dyn., 12, 325-357.

Sperber, K. R., S. Gualdi, S. Legutke, and V. Gayler, 2005: The Madden-Julian oscillation in ECHAM4 coupled and uncoupled general circulation models. Climate Dyn., 25, 117140.

Straub, K. H., and G. N. Kiladis, 2003: Interactions between the boreal summer intraseasonal oscillation and higherfrequency tropical wave activity. Mon. Wea. Rev., 131, 945960.

Takayabu, Y. N., 1994: Large-scale cloud disturbances associated with equatorial waves. Part I: Spectral features of the cloud disturbances. J. Meteor. Soc. Japan, 72, 433-448.

—, T. Iguchi, M. Kachi, A. Shibata, and H. Kanzawa, 1999: Abrupt termination of the 1997-98 El Niño in response to a Madden-Julian oscillation. Nature, 402, 279-282.

Tiedtke, M., 1989: A comprehensive mass flux scheme for cumulus parameterization in large-scale models. Mon. Wea. Rev., 117, 1779-1800.

Tokioka, T., K. Yamazaki, A. Kitoh, and T. Ose, 1988: The equatorial 30-60-day oscillation and the Arakawa-Schubert penetrative cumulus parameterization. J. Meteor. Soc. Japan, 66, 883-901.

Waliser, D. E., 2005: Predictability and forecasting. Intraseasonal Variability of the Atmosphere-Ocean Climate System, W. K. M. Lau and D. E. Waliser, Eds., Springer, 389-418.

_ K. M. Lau, and J. H. Kim, 1999: The influence of coupled sea surface temperatures on the Madden-Julian oscillation: A model perturbation experiment. J. Atmos. Sci., 56, 333358.

W. Stern, and C. Jones, 2003a: Potential predictability of the Madden-Julian oscillation. Bull. Amer. Meteor. Soc., 84, 33-50.

, S. Schubert, A. Kumar, K. Weickmann, and R. Dole, 2003b: Proceedings from a workshop on "Modeling, Simulation and Forecasting of Subseasonal Variability." NASA/CP 2003104606, Vol. 25, 62 pp.

- W. Stern, S. Schubert, and K. M. Lau, 2003c: Dynamic predicatability of intraseasonl variability associated with the Asian summer monsoon. Quart. J. Roy. Meteor. Soc., 129, 2897-2925.

- and Coauthors, 2003d: AGCM simulations of intraseasonal variability associated with the Asian summer monsoon. Climate Dyn., 21, 423-446.

Wang, B., and H. L. Rui, 1990: Synoptic climatology of transient tropical intraseasonal convective anomalies: 1975-1985. Meteor. Atmos. Phys., 44, 43-61.

Wang, W., and M. E. Schlesinger, 1999: The dependence on convective parameterization of the tropical intraseasonal oscillation simulated by the UIUC 11-layer atmospheric GCM. $J$. Climate, 12, 1423-1457.

Weickmann, K. M., G. R. Lussky, and J. E. Kutzbach, 1985: Intraseasonal (30-60 day) fluctuations of outgoing longwave radiation and $250 \mathrm{mb}$ streamfunction during northern winter. Mon. Wea. Rev., 113, 941-961.

- G. Kiladis, and P. Sardeshmukh, 1997: The dynamics of intraseasonal atmospheric angular momentum oscillations. $J$. Atmos. Sci., 54, 1445-1461.

Wheeler, M., 1998: Convectively coupled equatorial waves. Ph.D. thesis, University of Colorado, Boulder, CO, $164 \mathrm{pp}$.

_ 
waves: Analysis of clouds and temperature in the wavenumber-frequency domain. J. Atmos. Sci., 56, 374-399.

—_, and K. M. Weickmann, 2001: Real-time monitoring and prediction of modes of coherent synoptic to intraseasonal tropical variability. Mon. Wea. Rev., 129, 2677-2694.

—- and H. H. Hendon, 2004: An all-season real-time multivariate MJO index: Development of an index for monitoring and prediction. Mon. Wea. Rev., 132, 1917-1932.

__ and J. L. McBride, 2005: Australian-Indonesian monsoon. Intraseasonal Variability in the Atmosphere-Ocean Climate System, W. K. M. Lau and D. E. Waliser, Eds., Springer Praxis, 125-173.

— , G. N. Kiladis, and P. J. Webster, 2000: Large-scale dynamical fields associated with convectively coupled equatorial waves. J. Atmos. Sci., 57, 613-640.

Yasunari, T., 1979: Cloudiness fluctuations associated with the Northern Hemisphere summer monsoon. J. Meteor. Soc. Japan, 57, 227-242.

Yu, J.-Y., C. Chou, and J. D. Neelin, 1998: Estimating the gross moist stability of the tropical atmosphere. J. Atmos. Sci., 55, 1354-1372.

Yuter, S. E., and R. A. Houze Jr., 2000: The 1997 Pan American Climate Studies Tropical Eastern Pacific Process Study. Part I: ITCZ region. Bull. Amer. Meteor. Soc., 81, 451-481.

Zhang, C., and M. Dong, 2004: Seasonality in the Madden-Julian oscillation. J. Climate, 17, 3169-3180.

Zhang, G. J., and N. A. McFarlane, 1995: Sensitivity of climate simulations to the parameterization of cumulus convection in the CCC-GCM. Atmos.-Ocean, 3, 407-446.

_ and M. Mu, 2005: Simulation of the Madden-Julian Oscillation in the NCAR CCM3 using a revised Zhang-McFarlane convection parameterization scheme. J. Climate, 18, 40464064.

Zipser, E. J., 1969: The role of organized unsaturated convective downdrafts in the structure and rapid decay of an equatorial disturbance. J. Appl. Meteor., 8, 799-814.

_- 1977: Mesoscale and convective-scale downdrafts as distinct components of squall-line structure. Mon. Wea. Rev., 105, $1568-1589$. 